\title{
Discovery of conformation-sensitive anti-amyloid protofibril monoclonal antibodies using an engineered chaperone-like amyloid-binding protein
}

W Vallen Graham¹, Alessandra Bonito-Oliva¹, Rita Agostinelli², Riyaz Karim², Jeremy Deguzman $^{3}$, Kerry Kelleher2, Marianne Petro4, Anna-Karin Lindström4, Caroline Graff4,5, Kathleen M. Wood ${ }^{6}$, Lioudmila Tchistiakova², Kimberly Marquette ${ }^{2}$, Paul D. Wes ${ }^{3}$, Thomas P. Sakmar1,4*

${ }^{1}$ Laboratory of Chemical Biology \& Signal Transduction, The Rockefeller University, 1230 York Avenue, New York, NY 10065, USA

Biomedicine Design, Pfizer Worldwide Research and Development, 610 Main Street, Cambridge, MA 02139, USA

${ }^{3}$ Centers for Therapeutic Innovation, Pfizer, 450 E 29 $9^{\text {th }}$ Street, New York, NY 10016, USA ${ }^{4}$ Department of Neurobiology, Care Sciences and Society, Center for Alzheimer Research, Division of Neurogeriatrics, Karolinska Institutet, 14157 Huddinge, Sweden

5Theme Aging, Genetics Unit, Karolinska University Hospital- Huddinge, 14186 Stockholm, Sweden

${ }^{6}$ Neuroscience and Pain Research Unit, Pfizer Worldwide Research and Development, 610 Main Street, Cambridge MA 02139, USA

Corresponding author:

* Thomas P. Sakmar

e-mail: sakmar@rockefeller.edu 


\section{Abstract}

The hypothesis that amyloid beta peptides $(A \beta)$ are central to the pathogenesis of sporadic Alzheimer's disease (AD) is still hotly debated. Although several monoclonal antibodies (mAbs) against $A \beta$ have failed in therapeutic clinical trials, two conformation-selective, anti-A $\beta$ mAbs continue to show promise. A significant challenge has been to discover mAbs that preferentially target $A \beta$ protofibrils over natively-folded monomeric peptides or amyloid plaques. We have engineered a novel chaperone-like amyloid-binding protein (CLABP), Nucleobindin 1 (NUCB1), which enables the stabilization of protofibrils, allowing them to be used as immunogens in mice to facilitate the generation of $m A b s$ that recognize $A \beta$ protofibrils. An immunization campaign and subsequent screening funnel identified a panel of mAbs with high-affinity to $A \beta$. Two mAbs in particular, 1A8 and 7C8, displayed significant conformation sensitivity and preferentially bound $A \beta$ protofibrils over monomers. Furthermore, $1 A 8$ delayed $A \beta$ aggregation, but did not prevent eventual fibril formation, while 7C8 significantly and dose-dependently reduced fibril formation by inhibiting both primary and secondary nucleation. Both mAbs protected against protofibril-induced cytotoxicity in vitro, and showed distinctive staining patterns by immunohistochemistry in PS1/APP mice and in post-mortem AD brain tissue. In summary, we describe a novel method to stabilize soluble $A \beta$ protofibrils for use in immunization campaigns. We hypothesize that the stabilized protofibrils retain the neoepitopes of the $A \beta$ protofibril and the aggregates found in mouse models of disease and post-mortem AD brain tissue. 


\section{Introduction}

While many aging-associated diseases, such as cardiovascular disease, cancer, and hypertension, have benefited from improved diagnostics, medical procedures, and therapeutics, early diagnosis and disease-modifying therapeutics remain urgently needed for Alzheimer's disease (AD). AD is the leading cause of age-related dementia and is one of the top global healthcare challenges of our time. There are currently 35 million people afflicted with AD and related dementias worldwide, and this number is expected to reach over 100 million by 2050 if prevention strategies are not approved [1, 2].

The clinical manifestations of AD include a progressive increase in confusion and memory deficits, eventually resulting in a diagnosis of cognitive impairment. Pathologically, AD is defined by the presence of amyloid plaques and neurofibrillary tangles, composed of beta-amyloid (A $)$ and tau, respectively. The leading risk factor for $A D$ is age, although genetic and environmental factors contribute to the disease occurrence. The complex multi-domain molecular and cellular pathophysiological nature of suspected disease-causing events has resulted in disagreement in the research community as to the optimal target of potential therapeutics. Currently, there are no approved therapeutics that prevent or even slow the progression of AD or related dementias. As of 2017, there were 54 drugs with disease-modifying indications in Phase II or Phase III clinical trials [3]. Of these entities, $65 \%$ target pathways related to $A \beta$ or tau. While many factors are hypothesized to contribute to the etiology of sporadic $A D[4,5], A \beta$ is likely to play a key role in the molecular pathophysiology of $A D$. Not only is $A \beta$ the primary component of plaques, but mutations in genes involved in $A \beta$ processing and/or aggregation cause dominant, early-onset familial forms of $A D$ : mutations can be found both in the substrate (amyloid precursor protein, APP) [6] and the protease (presenilin) that work together to form $A \beta$.

One approach to target and engage $A \beta$ pathology is to use passive immunization with anti$A \beta$ antibodies. Of the seven immunotherapy drug entities with known anti-A $\beta$ mechanism of 
action undergoing clinical trials [7, 8], two bind the soluble monomer, four bind to an aggregated form (either oligomers, protofibrils or fibrils), and one is a polyclonal IVIG preparation. While clinical trials for immunotherapies that target the soluble monomer have experienced failures in the past, the emerging approach of targeting soluble $A \beta$ aggregates (oligomers or protofibrils) is showing promising results in ongoing trials [9]. Targeting the soluble pathophysiological form of early $A \beta$ aggregates is appealing, but these conformation-sensitive monoclonal antibodies (mAbs) are extremely hard to discover due to the transient nature and structural polymorphism of the protofibril [10]. The mAb BAN2401 (BioArtic Neuroscience AB, Biogen, Inc., Eisai Co., Ltd.) was developed following the discovery that the Arctic mutation in the APP gene yields a higher propensity for protofibril species compared with fibril formation. Therefore, the protofibrils originating from the Arctic mutant $A \beta 42$ were used to immunize mice and produce a humanized mAb that selectively recognizes protofibrils over monomers and fibrils [11]. Aducanumab (Biogen, Inc.) was discovered using a reverse translational medicine approach whereby B cell libraries were made using blood from aged, cognitively normal human donors. This fully human $\lg \mathrm{G} 1 \mathrm{mAb}$ binds to and reduces $A \beta$ aggregates [12].

Stabilizing and maintaining the protofibril structure is challenging. One approach has been to chemically stabilize [13-22] or induce cysteine mutations in the $A \beta$ peptide [23]. However, it is not clear that these $A \beta$ protofibrils result in disease-relevant neoepitopes for mAb production. An alternative strategy was used to produce the $A 11$ polyclonal antibody [24]. $A \beta 40$ peptide monomers were coated onto gold particles and immunized into mice, yielding a polyclonal pool of antibodies reactive against soluble aggregates of different amyloid sources. An alternative method for $A \beta$ protofibril stabilization is to use naturally existing or engineered amyloid-binding proteins.

Chaperone-like amyloid binding proteins (CLABPs) are an emerging class of proteins that could be useful for capture and stabilization of various amyloid intermediate states. For 
example, the engineered ZAß3 affibody binds to and stabilizes the $\beta$-sheet hairpin loop in misfolded $A \beta$ monomers that is similar, though not identical, to the $\beta$ hairpin found in amyloid fibrils $[25,26]$. Similarly, the DNAJB6 molecular chaperone binds to misfolded monomers of amyloid from multiple amyloidogenic peptide sources [27-29]. The protein chaperone domain, Bri2-BRICHOS extends the $A \beta$ lag phase of aggregation by maintaining an unstructured monomer [30]. Clusterin, on the other hand, can bind to amyloid oligomers through interaction with biologically active exposed hydrophobic patches [31]. We have recently characterized the ubiquitously expressed protein, Nucleobindin 1 (NUCB1), as a novel CLABP that potently stabilizes amyloid protofibrils from multiple sources [32]. Notably, NUCB1 binding and stabilization preserves the protofibril morphology and detoxifies the amyloid intermediate [32, 33], thereby making the chaperone-like effect of NUCB1 unique in this class of proteins.

We hypothesized that NUCB1-stabilized protofibrils could be isolated and used as immunogens for the discovery of high-affinity, conformation-sensitive mAbs. Here we report the discovery of two such mAbs, $1 \mathrm{~A} 8$ and $7 \mathrm{C} 8$, that preferentially target the protofibril over the monomer, as determined by ELISA and surface plasmon resonance (SPR). These mAbs show functional binding through kinetic inhibition of $A \beta 42$ aggregation and, importantly, display a protective function against $A \beta 42$ in cell toxicity assays. Immunohistochemistry studies on PS1/APP mice showed staining of amyloid plaques, whereas staining of human AD cortex also showed intracellular staining, staining near vessel walls, as well as at dense plaques and diffuse plaque-like structures. Therefore, NUCB1-stabilized A 342 protofibrils retain neoepitopes of the protofibril state and can be used to discover high-affinity conformation-sensitive anti-protofibril antibodies.

\section{Materials and Methods}

\section{Ethics statement}


All animal tissue samples were collected from animals in accordance with regulations and established guidelines, including review and approval by Pfizer's Institutional Animal Care and Use Committee. The Brain Bank at Karolinska Institute provided human tissue from voluntary donations after informed consent. All sections of this report adhere to the ARRIVE Guidelines for reporting animal research [34]. A completed ARRIVE guidelines checklist is included in Checklist S1.

\section{Production of A $\mathrm{\beta} 42$ monomers and protofibrils}

$A \beta 42$ and $A \beta 40$ synthetic peptides (American Peptide Company, Cat \# 62-0-80) were solubilized in hexafluoroisopropanol (HFIP) at $1 \mu \mathrm{g} / \mu \mathrm{l}$ for $1 \mathrm{~h}$ at room temperature with occasional vortexing, and sonicated in a water bath sonicator (VWR Model 50HT) for 10 minutes. Samples were aliquoted in low-retention tubes (Fisher, Cat \# 02-681-320) at 30 $\mu \mathrm{g} / \mathrm{tube}$, dried with a speed vac, and stored at $-80^{\circ} \mathrm{C}$. The peptide was then reconstituted in 2 $\mathrm{mM} \mathrm{NaOH}$ to $1 \mu \mathrm{g} / \mu \mathrm{l}$, sonicated in a water bath for 1 minute, dried down in a preheated speed vac for 30 minutes, stored at $-80^{\circ} \mathrm{C}$ and used within $24 \mathrm{~h}$ by diluting in cell media (for the cytotoxicity assay) or 20 mM Sodium Phosphate, pH8.0 (in all other cases). A 342 monomers were immediately used for experiments, while $A \beta 42$ protofibrils were obtained by incubating the peptide at $10 \mu \mathrm{M}$ monomeric concentration for $1 \mathrm{~h}$ at $37^{\circ} \mathrm{C}$ under quiescent conditions (i.e., without shaking).

\section{mtNUCB1-capped Aß42 protofibrils}

Recombinant expression of the engineered, soluble and $\mathrm{Ca}^{2+-f r e e ~ s N U C B 1}$ ( $m$ tNUCB1) has been previously described [32]. $20 \mu \mathrm{M} \mathrm{A} 342$ was co-incubated together with $5 \mu \mathrm{M} m t \mathrm{NUCB} 1$ in $20 \mathrm{mM}$ Sodium Phosphate $\mathrm{pH} 8.0$ for $24 \mathrm{~h}$, at $37^{\circ} \mathrm{C}$ in quiescent conditions. The cappedprotofibril containing solution was then applied to a Superdex200 26/60 PG SEC column (GE 
Healthcare, Piscataway, NJ) equilibrated with $20 \mathrm{mM}$ sodium phosphate, $\mathrm{pH}$ 8.0, $150 \mathrm{mM} \mathrm{NaCl}$. The relevant peak was collected for subsequent experiments.

\section{Immuno-Electron Microscopy}

$m+N U C B 1-c a p p e d A \beta 42$ protofibrils isolated through size exclusion chromatography (SEC) were imaged by double immuno-electron microscopy (EM), as described in [32]. The sample was co-incubated with the mouse anti-A 6 E10 (BioLegend, 1:100) antibody and the rabbit antiNUCB1 (Aviva Systems Biology, 1:100) antibody in solution for $20 \mathrm{~min}$ at room temperature. Successively, the sample was diluted to $5 \mu \mathrm{M}$ and placed in a volume of $5 \mu$ l onto a carbon film 200-mesh copper grid for 2 min, followed by a 3 min incubation with 3\% BSA. The grid was then incubated for 20 min with an anti-rabbit $12 \mathrm{~nm}$ gold-conjugated secondary antibody together with an anti-mouse $6 \mathrm{~nm}$ gold-conjugated secondary antibody (Jackson Laboratories, 1:20). The grid was then extensively rinsed in buffer and counterstained with $1 \%$ aqueous uranyl acetate solution. Samples were viewed with a JEOL 1400 Plus transmission electron microscope (TEM) and images acquired with Gatan $2 \mathrm{~K}$ x 2K digital camera.

\section{Atomic Force Microscopy}

The $m t$ NUCB1-A 342 protofibrils were further imaged by atomic force microscopy (AFM), as previously described [32]. Briefly, the sample was diluted to the desired working concentration and immediately plated $(40 \mu \mathrm{l})$ on freshly cleaved mica (SPI). After a $10 \mathrm{~s}$ incubation, the sample was washed under a gentle stream of $10 \mathrm{ml}$ molecular biology grade $\mathrm{H}_{2} \mathrm{O}($ Fisher BP2819-1) before being blown dry with $\mathrm{N}_{2}$ gas and immediately placed under the AFM stage. High-resolution images ( $1 \mu \mathrm{m} \times 1 \mu \mathrm{m}, 512 \times 512$ pixels) were acquired in air using a combination of the Cypher ES and the MFP-3D-BIO AFMs (Asylum Research, Goleta, CA) and in tapping mode using Olympus AC240TS-R3 probe (Asylum Research, Goleta CA). Each 
segmented structure was then cropped into its own individual image, a bicubic interpolation was applied, and montages of individual protofibrils were created.

\section{Immunization campaign}

Three BALB/c mice (The Jackson Laboratory) were immunized subcutaneously and intraperitoneally with a total of $20 \mu \mathrm{g}$ of freshly prepared $m t$ NUCB1-capped A $\beta$ protofibrils, and boosted three additional times every $14 \mathrm{~d}$. Blood was collected $7 \mathrm{~d}$ after the second boost. Two mice with high serum reactivity to $m+N U C B 1-A \beta$ were boosted a final time $2 \mathrm{~d}$ after the third boost. $5 \mathrm{~d}$ later, the mice were euthanized by low-flow carbon dioxide overexposure followed by exsanguination by cardiac puncture and spleens were harvested for hybridoma fusions.

\section{Hybridoma fusions and screening}

The mouse spleens were fused with P3 myeloma cells (ATCC Cat \# CRL1580) according to published methods [35]. Hybridoma supernatants were screened for $m+N U C B 1$ and $A \beta$ protofibril reactivity using ELISAs. Of 2,208 supernatants screened, 80 A $\beta$ protofibril-specific hybridomas were selected for retesting using a cut-off value of 0.6 OD. Of $108 m t N U C B 1-$ specific hybridomas (OD > 0.6), ten were selected for further testing. In addition, two mtNUCB1 and $A \beta$ protofibril cross-reactive hybridomas were selected for further testing. Confirmed hits were further subcloned to ensure monoclonality. Subclones that retained activity were cloned recombinantly into an expression vector containing the human Fc antibody constant region.

\section{ELISA}

In the Sandwich ELISA format, $10 \mu \mathrm{g} / \mathrm{ml}$ of the capture, anti-A $\beta \mathrm{N}$-terminus antibody [36] were coated on clear 96-well plates (Costar \#3590) overnight at $4^{\circ} \mathrm{C}$. A 342 monomer or 
protofibril was added at $1 \mu \mathrm{M}$ and incubated for $1 \mathrm{~h}$ at room temperature. Test antibodies were added, incubated for $1 \mathrm{~h}$ at room temperature, and successively detected with appropriate HRP conjugated secondary antibodies. ELISAs were developed with TMB One Component HRP Microwell Substrate (TMBW-1000-01) and then stopped with $0.18 \mathrm{M}$ sulfuric acid. Absorbance at $450 \mathrm{nM}$ was read on Envision plate reader (Perkin Elmer).

Similarly, direct ELISA wells were coated with antigen in PBS overnight at $4{ }^{\circ} \mathrm{C}$. Test hybridoma supernatants were added, incubated for $1 \mathrm{~h}$ at room temperature, and successively detected with appropriate HRP conjugated secondary antibodies and developed with TMB.

To measure the solution competition of antibodies to immobilized $A \beta 42$ protofibrils by soluble monomeric $A \beta 40$, black 96-well maxisorp plates (NUNC) were coated with $A \beta 42$ protofibrils diluted in coating buffer at a concentration of $2.5 \mu \mathrm{g} / \mathrm{ml}(555.6 \mathrm{nM})$ overnight at $4{ }^{\circ} \mathrm{C}$. The following day the plate was washed and blocked with TBST containing $1 \%$ BSA for $1 \mathrm{~h}$ at room temperature and successively incubated with a fixed concentration ( $0.4 \mathrm{nM})$ of antibody (hu1A8, mt1A8, hu7C8, mt7C8, or the $A \beta N$-terminus binding $6 E 10$ ) together with decreasing concentrations of $\mathrm{A} \beta 40$ monomers, starting at $10 \mu \mathrm{M}$ and diluted in half-logs. The binding was detected with appropriate HRP conjugated secondary antibodies and Amplex UltraRed (Thermo \# A36006).

\section{Surface Plasmon Resonance}

The surface plasmon resonance (SPR) characterization of an $\mathrm{N}$-terminal A $\beta$ peptide DAEEG (DAEFRHDSGYSGKQKSRNEGKGGC) binding to anti-mouse captured antibodies from hybridoma supernatants was performed using a BIAcore T-200 instrument (GE Healthcare, Marlborough, MA) [36]. The sample and running buffer was HBS-EP, pH 7.4 (10 mM HEPES, $150 \mathrm{mM} \mathrm{NaCl}, 3 \mathrm{mM}$ EDTA, and 0.05\% P20). An anti-mouse antibody (GE Healthcare, BR100838) was covalently coupled to a CM5 sensor chip (GE Healthcare, BR100530) following 
the manufacturer's recommendations. Mouse hybridoma antibodies at $0.5 \mu \mathrm{g} / \mathrm{mL}$ were captured for 120 s on flow cells 2,3 , or 4 with flow cell 1 used as a reference. The DAE-EG peptide was diluted to $500 \mathrm{nM}$ and injected over the sensor chip surface for $120 \mathrm{~s}$ at a flow rate of $50 \mu \mathrm{l} / \mathrm{min}$. Dissociation data was collected for $300 \mathrm{~s}$ post injection followed with three $60 \mathrm{~s}$ regeneration pulses of $10 \mathrm{mM}$ Glycine $\mathrm{pH} 1.5$, and 1 pulse of HBS-EP, $\mathrm{pH}$ 7.4. The sensorgram data was collected at $1 \mathrm{~Hz}$, double referenced [37], and fit to a 1:1 Langmuir model using BIAcore T200 evaluation software version 3.0. The triage quality equilibrium dissociation constant $K_{D}$ was determined with the equation $\mathrm{K}_{\mathrm{D}}=\mathrm{kd}(1 / \mathrm{s}) / \mathrm{ka}(1 / \mathrm{Ms})$.

The SPR studies to determine conformation binding of the human chimeric $1 \mathrm{~A} 8$ and $7 \mathrm{C} 8$ mAbs were carried out with the ProteOn XPR36 protein interaction array system (Bio-Rad) based on SPR technology. The antibodies (1A8 and 7C8) were immobilized in the vertical direction on GLM sensor chips (Bio-Rad) using amine-coupling chemistry, as described previously [38], followed by a blocking step with ethanolamine. The anti-A $\beta 6 \mathrm{E} 10$ (Bio-Legend) antibody and the mouse IgG antibody 1D4 were used as positive and negative control, respectively. The final immobilization level was about 6500 resonance units $\left(1\right.$ resonance unit $=1 \mathrm{pg}$ protein $\left./ \mathrm{mm}^{2}\right)$ for all the antibodies. Successively, $\mathrm{A} \beta 42$ protofibrils obtained by incubating $10 \mu \mathrm{M} A \beta 42$ for 60 min at $37^{\circ} \mathrm{C}$ or freshly solubilized $\mathrm{A} \beta 40$ monomers were diluted in $20 \mathrm{mM}$ Sodium Phosphate $\mathrm{pH} 8.0$ and flowed over the chip surface, in the horizontal direction, for $60 \mathrm{~s}$ at a flow rate of $30 \mu \mathrm{l} / \mathrm{ml}$. The assays were performed at $25^{\circ} \mathrm{C}$ and the data were normalized by interspot and by buffer.

\section{Octet}

An OctetRED 384 instrument (ForteBio, Menlo Park, CA) was used to characterize binding of $m \mathbb{N} U \mathrm{CB} 1$-capped $\mathrm{A} \beta 42$ protofibrils and freshly prepared protofibrils without $m+\mathrm{NUCB} 1$ to mouse hybridoma antibodies. The mouse hybridoma antibodies were diluted to $10 \mu \mathrm{g} / \mathrm{ml}$ in PBS 
and loaded for $400 \mathrm{~s}$ onto an anti-mouse Fc biosensor (ForteBio, 18-5089). A baseline was established in Kinetics buffer (ForteBio, 18-5032) for $180 \mathrm{~s}$, followed by a $300 \mathrm{~s}$ association and dissociation of $m+N U C B 1-A \beta 42$ at $\sim 300 \mathrm{nM}$ or protofibrils at $\sim 900 \mathrm{nM}$. The Octet assay was conducted at ambient temperature. The data was double referenced [37] and analyzed with BIAevaluation software version 4.1.1.

\section{Fab fragments purification}

$1 \mathrm{~A} 8$ and $7 \mathrm{C} 8 \mathrm{lgGs}$, as well as the control lgG, were digested with immobilized papain protease and Fab fragments were purified using Protein A agarose (Pierce Fab Preparation Kits). The success of the digestion reaction was assessed by native SDS-PAGE gel.

\section{Thioflavin $\mathrm{T}$ binding assay}

The kinetics of aggregation of $\mathrm{A} \beta 40(40 \mu \mathrm{M})$ was measured by incubating the peptide with thioflavin $\mathrm{T}(\mathrm{ThT})(10 \mu \mathrm{M})$ (Fisher Scientific). The kinetics of aggregation of $\mathrm{A} \beta 42(10 \mu \mathrm{M})$ was tested in the presence of equimolar concentration of the whole $\lg G$ antibody $1 \mathrm{~A} 8,7 \mathrm{C} 8$, or negative control (10 $\mu \mathrm{M}$, Ultra-LEAF Purified Human IgG1 isotype control, Biolegend \#403502) or different concentrations $(2.5,5,7.5$ or $10 \mu \mathrm{M})$ of their corresponding digested Fab fragments and ThT $(10 \mu \mathrm{M})$. A volume of $50 \mu$ per well ( $=4 /$ group) was added to each well of a prechilled $\left(4^{\circ} \mathrm{C}\right)$ Corning 96 -well half area black with clear flat bottom polystyrene with non-binding surface (NBS) and covered with clear self-adhesive topseal. The aggregation was tested every 10 min under quiescent conditions for up to $7 \mathrm{~d}$ at a constant temperature of $25^{\circ} \mathrm{C}$ (for $\mathrm{A} \beta 40$ ), or $24 \mathrm{~h}$ at $37^{\circ} \mathrm{C}$ (for $\left.\mathrm{A} \beta 42\right)$. Fluorescence measurements were performed on a Flexstation II (Molecular Devices) using an excitation wavelength of $450 \mathrm{~nm}$ and an emission wavelength of $485 \mathrm{~nm}$. The obtained fluorescence measures were normalized to the relative fluorescence expressed after 20 min of incubation. 


\section{Rate constant calculation}

Rate constants of aggregation (primary nucleation, elongation and secondary nucleation) were calculated with AmyloFit online software [39] and simulations were performed to determine how antibody Fab affects the global $A \beta 42$ aggregation profile by interfering with and inhibiting microscopic aggregation event(s). First, following the preliminary steps in the AmyloFit pipeline, we chose time windows from reaction start point to plateau and normalized the values to 1 . The fitted model of secondary nucleation dominant aggregation was chosen according to the guidelines published in [40]. Successively, the model parameters [initial monomer concentration $\left(m_{0}\right)$, initial fibril number concentration $\left(P_{0}\right)$, initial fibril mass concentration $\left(M_{0}\right)$, reaction order of primary nucleation $\left(n_{c}\right)$ and reaction order of secondary nucleation $\left(n_{2}\right)$ ] were set to Global constant (see tables for specific values) and each time one of the rate constants was set to 'Fit' while the others were set to 'Global fit'. We made sure convergence was attained by increasing the Basin Hops and observing no change in the MRE. The fitting results expressed as MRE and residuals over reaction time were analyzed and shown in each of these specific fittings separately.

\section{Cytotoxicity assay}

Cytotoxicity assays were performed using adherent PC12 cells (CRL01721.2, ATCC). Experiments were only conducted if cells were above $90 \%$ viable. Cells were diluted to a concentration of $3.2 \times 10^{5}$ cells $/ \mathrm{ml}$ in assay media: DMEM/F-12, no phenol red (GIBCO, Cat \# 21040-025), 0.5\% FBS, non-heat inactivated (ATCC, Cat \# 30-2020). $80 \mu$ l of cell suspensions were added to flat-bottomed, black-walled 96-well plates (Corning, Cat \# 3340 CellBIND), for a final amount of 25,600 cells per well, and incubated overnight. On the following day, $\mathrm{NaOH}-$ treated $A \beta 42$ was diluted in assay media, sonicated in a water bath for $1 \mathrm{~min}$ and either used 
immediately to test monomerics, or incubated at $10 \mu \mathrm{M}$ monomeric concentration at $37^{\circ} \mathrm{C}$ for 1 h, protected from light, to test protofibrils, and successively diluted to the final concentration.

To determine the $\mathrm{EC}_{80}$ of monomers and protofibrils, the samples were added to cells seeded the day before at an initial concentration of $1 \mu \mathrm{M}$ and $3 \mu \mathrm{M}$, respectively, diluted half logs across the plate and incubated overnight.

To test the protective effect of the antibodies, $20 \mu$ of $A \beta 42$ monomers or protofibrils were added at $\mathrm{EC}_{80}$ concentrations ( $800 \mathrm{nM}$ or $30 \mathrm{nM}$, respectively) to cells seeded the day before and the concentration kept fixed across the plates. At the same time, 1A8, 7C8, or negative control were added to the peptide at over a range of concentrations.. Cells were incubated overnight, and viability was measured using the Roche MTT (3-(4,5-dimethylthiazol-2-yl)-2,5diphenyl tetrazolium bromide) kit (Roche, Cat \# 11465007001) according to manufacturer's instructions.

\section{Immunohistochemistry in mouse tissue}

Adult (male) PS1(G384A)/APPsw (PS1/APP) transgenic mice were ordered from Taconic (Pfizer generated line), housed in groups of four and given $5 \mathrm{~d}$ to acclimate to the housing facility. Environmental conditions were compliant with approved protocols. During housing, animals were monitored twice daily for health status. No adverse events were observed.

PS1/APP transgenic mice and non-transgenic littermate controls were euthanized by lowflow carbon dioxide overexposure followed by exsanguination by cardiac puncture, and perfused with saline. Brains were harvested, flash frozen in isopentane, sliced at $12 \mu \mathrm{m}$ thickness and stored at $-80^{\circ} \mathrm{C}$. At the time of use, sections were thawed for $5 \mathrm{~min}$ at room temperature. Microscope slides were submerged in Coplin jars containing 4\% paraformaldehyde for 60 min to prepare post-fixed sections for staining. Antigen retrieval was

performed using Rodent Decloaker (Biocare Medical, Walnut Creek, CA, Cat \# RD913) solution 
in a Decloaking Chamber (Biocare Medical, Walnut Creek, CA, Cat \# DC2012). To inactivate endogenous peroxidases and block non-specific binding sites, sections were treated with $0.3 \%$ hydrogen peroxidase, an Avidin/Biotin Blocking Kit (Vector Laboratories, Burlingame, CA, Cat \# SP-2001), and 10\% normal goat serum (Vector Laboratories, Burlingame, CA, Cat \# S-4000). Primary antibodies $1 \mathrm{~A} 8,7 \mathrm{C} 8$, a total anti-A $\beta \mathrm{mAb}$ and isotype control were prepared at $10 \mu \mathrm{g} / \mathrm{ml}$ and incubated with sections overnight in a humid chamber at $4^{\circ} \mathrm{C}$. The following day, sections were incubated with biotinylated secondary antibody (Bethyl Laboratories, Montgomery, TX) for 60 min. To visualize staining, sections were treated with the VECTASTAIN ELITE ABC-HRP Kit (Vector Laboratories, Cat \# PK-6100) and DAKO DAB+ Chromogen System (Agilent, Santa Clara, CA, Cat \# K3468) per manufacturer protocols. Slides were counterstained with hematoxylin, mounted, and then imaged on the Axio Scan.Z1 slide scanner (Carl Zeiss Microscopy GmbH, Jena, Germany).

\section{Immunohistochemistry in human tissue}

All brain materials were obtained from the Huddinge Brain Bank at Karolinska Institutet Alzheimer Disease Research Center. All familial AD subjects met the criteria for definitive AD according to the Consortium to Establish a Registry for AD (CERAD) 38. 1A8 and 7C8 target engagement was evaluated in formalin-fixed paraffin-embedded (FFPE) tissue sections from the frontal cortex of a patient diagnosed with definitive AD by CERAD and Braak V-VI as well as cerebral amyloid angiopathy. $5 \mu \mathrm{m}$ sections were sliced and stained with the murine version of the mAbs (1A8 mulgG2a-4m and 7C8 mulgG2a-4m) and compared to the anti-A $\beta$ N-terminus positive control antibody (6E10, Biolegend, Cat. \# \#SIG39320, diluted 1:1000) and an IgG negative control antibody (used at a concentration of $5 \mu \mathrm{g} / \mathrm{ml}$ ). The FFPE sections were deparaffinized in xylene and rehydrated in decreasing concentrations of ethanol. To retrieve antigens, all slides were treated with Diva Decloaker (Biocare Medical, Cat. \# DV2004MX) in a 
pressure cooker at $110^{\circ} \mathrm{C}$ for 30 min with the exception of the $6 \mathrm{E} 10$ stain slide that was treated with $70 \%$ Formic Acid for 20 min at room temperature. Endogenous peroxidase activity was successively blocked with Peroxidase (Dako kit, Cat. \# K4007) and the sections were incubated with normal goat serum diluted 1:20 in TBST for $20 \mathrm{~min}$ at room temperature. The sections were then incubated for $45 \mathrm{~min}$ room temperature in the respective primary antibody diluted in antibody diluent (Dako, Cat. \# S3022) and the signal detected using a HRP-DAB based detection system kit (Dako, Cat. \# K4007). Finally, nuclei were counterstained with Mayer's Hematoxylin using a standard protocol. After that, the sections were dehydrated in rising ethanol concentrations followed by clearing in xylene. The images were acquired with a Nikon Eclipse E800 microscope equipped with a 10x objective and the NIS-Elements F 4.30.01 software. Human sample collection and the protocols used in the study were approved by the Stockholm ethical review board, unit 1 (Stockholms regional etikprövningsnämnd avdelning 1) with the reference number 2011/962-13/1 on July 20, 2011 and all methods were performed in accordance with the relevant guidelines and regulation thereby established. The tissue was collected post-mortem at the Brain Bank at Karolinska Institute upon voluntary donation and informed consent (informed consent forms are available upon request).

\section{Statistical analysis}

Data were expressed as means \pm standard error (SEM). One- and Two-way analysis of variance (ANOVA) followed by a post-hoc Tukey's multiple comparisons test was used to analyze differences among groups. Statistical analyses were performed using GraphPad Prism 6.0 software (GraphPad Software Inc). Statistical differences for all tests were considered significant at the $p<0.05$ level. 


\section{Results}

\section{Preparation and characterization of stabilized A 342 protofibril immunogen}

Previously, we characterized an engineered version of the CLABP, mtNUCB1, as an inhibitor of amyloid aggregation, particularly $A \beta 42$ [32]. The conversion of $A \beta 42$ monomers into fibrils is incomplete in the presence of $m+N U C B 1$ through a proposed mechanism of $m+N U C B 1$ capping A 342 protofibril ends. Importantly, mtNUCB1 maintains A $\beta$ protofibril solubility and renders the aggregates non-toxic in a cell-based assay. The stable mtNUCB1-A 342 structures display a characteristic morphology of short protofibrils, being approximately $30 \mathrm{~nm}$ long, and $3.8 \mathrm{~nm}$ thick, and can be purified using size-exclusion chromatography (SEC) [32]. We hypothesize here that $m+N U C B 1-$ stabilized $A \beta 42$ protofibrils contain an array of neoepitopes that characterize the protofibril structure. Therefore, we aimed to discover high-affinity mAbs that bound to the quaternary conformations of the $A \beta$ protofibril. To this end, we purified sufficient $m+N U C B 1-A \beta 42$ protofibril complex to complete an immunization campaign of three mice.

We generated and enriched $m$ INUCB1-A 342 stabilized protofibrils using SEC and the relevant peak was collected and concentrated, as previously reported [32]. The A $\beta$ and NUCB1 content was confirmed with direct ELISA (S1 Fig A, B). Atomic force microscopy (AFM) was utilized to validate that the $m \mathbb{N}$ UCB1-A 342 complex retained the expected morphology as seen before, with similar length and height as previously observed [32] (S1 Fig C). Immuno-electron microscopy (EM) analysis of NUCB1- and A $\beta$-directed gold particles showed close proximity to an apparent protofibril structure (S1 Fig D). We therefore considered the immunogen to be robust and representative of $m+N U C B 1-A \beta 42$ protofibril complexes.

\section{Screening strategy and summary of screening campaign results}


The screening strategy and a summary of screening campaign results are illustrated in the schematic in Fig 1. The hybridoma supernatant fractions resulting from the immunization campaign were compared with pre-fusion bleeds, or negative controls, in an ELISA to detect $m t N U C B 1$-specific and Aß42-protofibril-specific activities (Fig 1 and Fig 2A). Relative binding activities of the samples indicate ranges of activity for $A \beta 42$ protofibrils and $m+N U C B 1$ separately, and a few supernatant fractions from the hybridoma wells that appear to have dual activity at varying levels, possibly due to mixed hybridoma populations. From the primary screening, a total of 80 hybridomas having $A \beta 42$ protofibril-binding activity over $0.6 \mathrm{OD}$, and $m+N U C B 1$ specific activity below 0.6 OD, were selected for further characterization (Fig 2A, blue circles). Of these, 57 fused lines were confirmed to be monoclonal and re-screened by singlepoint ELISA to compare binding to $A \beta 42$ monomers, protofibrils, $m \mathbb{N} U \mathrm{CB} 1$, and the original immunogen mtNUCB1-Aß42 protofibrils (Fig 2B). The results in this single-point ELISA show that many clones displayed preliminary desired characteristics of higher relative affinity to $A \beta 42$ protofibrils than $m \mathbb{N} \mathrm{NUCB} 1$. Some clones showed reactivity both to $m \mathbb{N} U \mathrm{CB} 1-\mathrm{A} \beta$ protofibrils and $m+N U C B 1$, suggesting that they may be reactive to $m+N U C B 1$. 


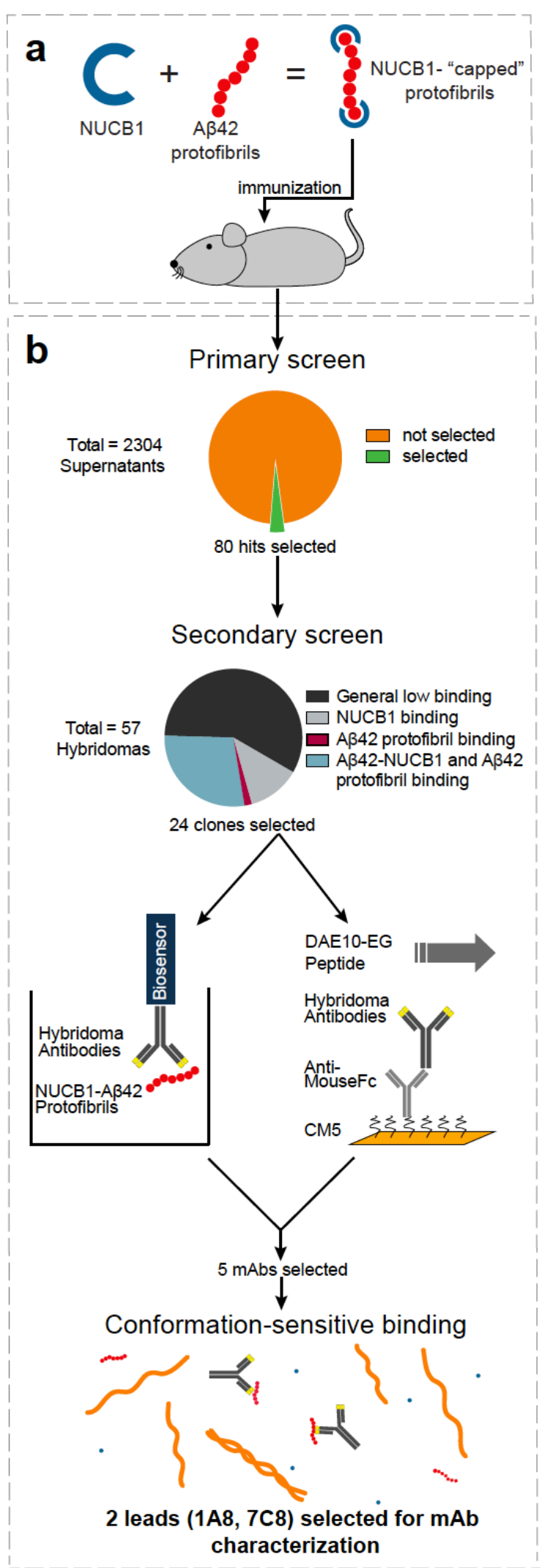

Figure 1. Screening strategy flow chart and immunization campaign summary results.

(A) Work flow schematic of the immunogen preparation. (B) Screening strategy flow chart. The hybridoma supernatants $(n=$ $2,304)$ were subjected to the primary screening by ELISA. Based on reactivity, 80 hits were selected and fused, and 57 clones were submitted to secondary screening by single-point ELISA. Twenty-four supernatants were subsequently tested by Octet Biosensor and Surface plasmon resonance (SPR) assays. Five selected clones were subcloned and screened for protofibril binding by sandwich ELISA. Finally, 2 lead mAbs were selected for further characterization. 
Based on their binding profile in this secondary screening, we selected 24 hybridomas (shown in Fig 2, lower panel) for further binding analysis. Specifically, of these clones, 16 showed high binding to $A \beta 42$ protofibrils and $m+N U C B 1-A \beta$ protofibrils, seven clones showed high $m+N U C B 1$ binding and one clone displayed preferential binding to $A \beta 42$ protofibrils.

a

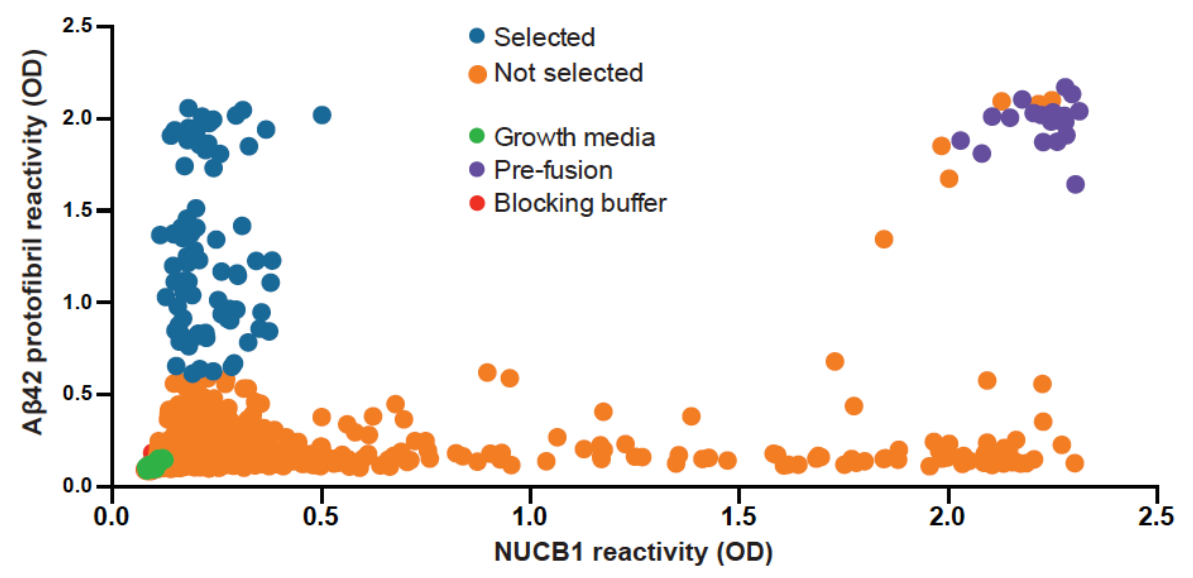

b
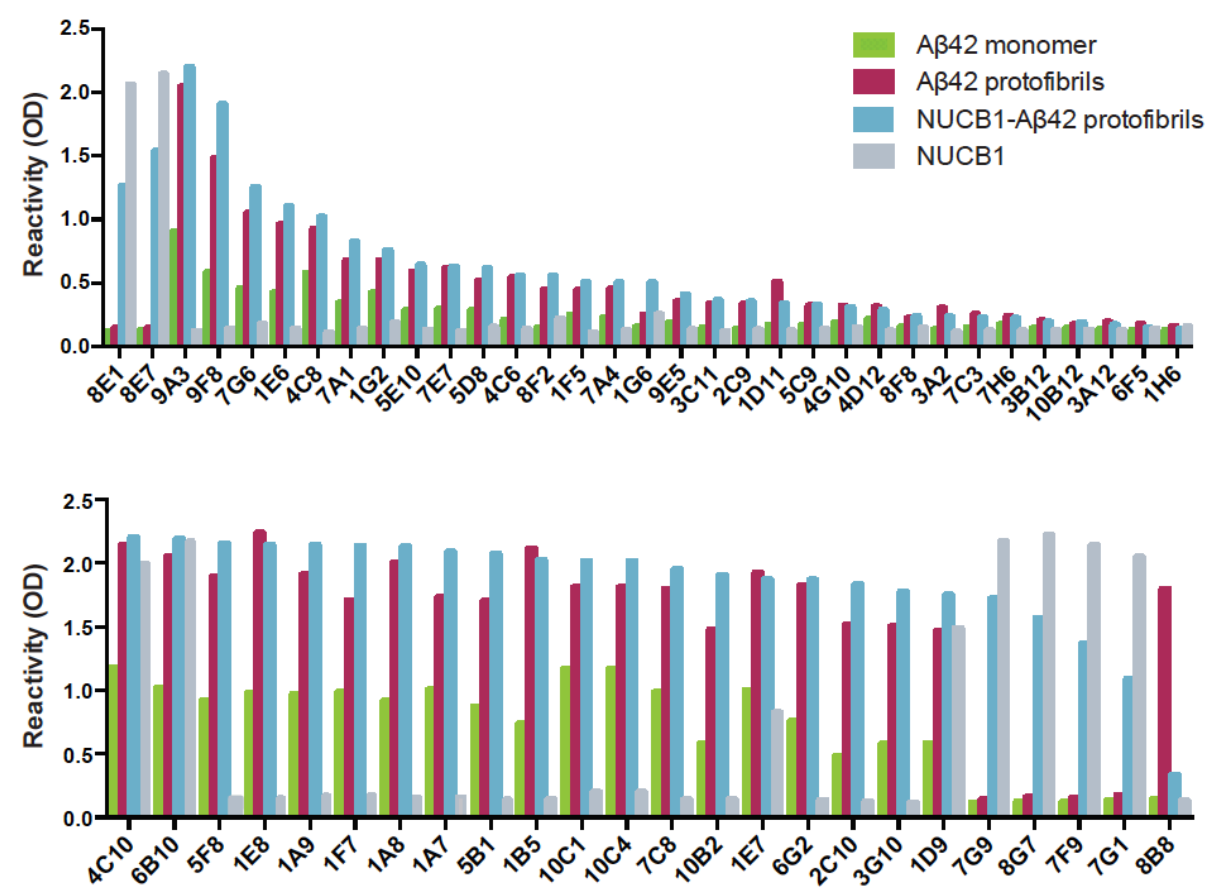

Figure 2. Generation of mAbs recognizing mtNUCB1-capped A $\beta$ protofibrils.

(A) Hybridoma cells were generated from the splenocytes of immunized mice and plated at 20,000 cells per well in 96-well plates. The supernatants of 2,304 hybridomas were screened for 
reactivity against $A \beta$ protofibrils and mtNUCB1. Hits that showed reactivity $>0.6 O D$ at $450 \mathrm{~nm}$ for $A \beta$ protofibrils, but < 0.6 for mtNUCB1, were selected. (B) 57 clones were re-tested for reactivity to mtNUCB1-A $\beta$ protofibrils and $m t N U C B 1$, as well as uncapped $A \beta$ protofibrils and $A \beta$ monomers, in a single-point ELISA. Based on the reactivity profile, 24 hybridomas (shown in the lower panel) were selected for further analysis.

\section{Octet Characterization of Hybridoma Supernatants}

To further determine the relative reactivity of 24 selected hybridoma supernatant antibodies against the immunogen (mtNUCB1-A 342 protofibrils) or A 342 protofibrils, we utilized a label free high-throughput Octet assay (Fig 1 and S2 Fig A). The results indicated that about half of the clones retained their antibody binding activity to both the immunogen and the $A \beta 42$ protofibrils. While some supernatant antibodies lost their binding activity to both antigens (i.e., 1A7, 3G10, 10B2, 10C4, 10B12, 1E8 and 8B8), a few (i.e., 4C10, 7F9, 8G7 and 7G1) showed strong binding to the immunogen, but lost activity against the $A \beta$ protofibrils.

\section{SPR Characterization of Hybridoma Supernatant Antibodies}

An SPR assay was used to characterize binding of the selected hybridoma supernatant antibodies to the $\mathrm{N}$-terminal, immune-dominant region of $A \beta$ [41]. To determine relative binding, a peptide containing the $\mathrm{N}$-terminal 1-10 amino acids of $A \beta$ was screened against the hybridoma supernatant antibodies (Fig 1). The results indicated that half of the supernatant antibodies bound to the $\mathrm{N}$-terminus $A \beta$ 1-10 peptide (S2 Fig B). We selected a total of five supernatants that demonstrated binding to the N-terminus $A \beta$ 1-10 peptide (i.e., 1A8, 7C8, 1D9, $1 \mathrm{E} 7$ and $6 \mathrm{G} 2)$, with $\mathrm{K}_{\mathrm{D}}$ values near $10 \mathrm{nM}$, including $1 \mathrm{~A} 8$ and 7C8. 1A8 and 7C8 showed the lowest and highest relative binding signal, respectively, though this difference may have been driven by different concentrations and degrees of aggregation in the relatively crude 
supernatants. All selected clones were processed for sequencing, subcloning and further characterization.

\section{Monomer versus protofibril binding affinities of cloned mAbs}

Antibody was purified from the five selected clones and tested against $A \beta 42$ monomers and protofibrils using a sandwich ELISA (S3 Fig). The range of $\mathrm{EC}_{50} \mathrm{~S}$ of each $\mathrm{mAb}$ for $\mathrm{A} \beta 42$ monomers ranged from 2.1 to $9.2 \mathrm{nM}$, while the range for protofibrils was from 2.8 to $5.8 \mathrm{nM}$ (S3 Fig). While the $\mathrm{EC}_{50} \mathrm{~S}$ are in close range, the overall signal for protofibril was higher than monomer for all antibodies, thus indicating that these antibodies have increased binding to the protofibril preparation. These results indicate that the $m \mathbb{N}$ UCB1-A 342 protofibril complex contains epitopes that are immunogenic, resulting in mAbs that have affinity to $A \beta$.

\section{Conformation-sensitive binding of $1 \mathrm{~A} 8$ and 7C8 expressed mAbs}

To produce stable antibody chimeras, we cloned the variable regions of both $1 \mathrm{~A} 8$ and $7 \mathrm{C} 8$ and incorporated these sequences onto a human IgG1 antibody backbone, with or without effector function, in suitable vectors for expression in mammalian cell lines. The effectorless mutant contains point mutations (L234A, L235A, and G237A) in the antibody heavy chain to decrease Fc receptor binding $[42,43]$. To validate that these clones retained their desired activity, we purified the human chimeric (hu1A8 and hu7C8) and the effectorless mutant (mt1A8 and mt7C8) mAbs and used them in a sandwich ELISA (Fig 3A, B) to compare relative binding to either $A \beta 42$ protofibrils or freshly prepared $A \beta 40$ monomer. In these experiments the $A \beta 40$ peptide was used as monomeric control because of its slow aggregation rate (S4 Fig), since A $\beta 42$ monomer would begin to aggregate during the course of the assay. The effectorless mAbs bound equivalently to their wild-type counterparts, with more binding occurring to lower concentrations of protofibrils, and achieving higher saturable binding than monomers. Since the 
apparent preferential binding of immobilized 1A8 and 7C8 to protofibrils in the ELISA format could be due to non-physiological avidity effects, we sought to determine whether preferential binding was also observed in a solution phase. Therefore, we performed an ELISA-based solution competition assay, which was recently used to demonstrate preferential binding of aducanumab to $A \beta$ oligomers (44). While monomeric $A \beta 40$ was able to compete for binding to the total $A \beta N$-terminal mAb, $6 E 10$, with an $\mathrm{EC}_{50}$ of $95 \mathrm{nM}$, minimal competition was observed for $1 \mathrm{~A} 8$ and $7 \mathrm{C} 8$, with only about $30 \%$ inhibition observed at the highest concentration tested (3 $\mu \mathrm{M})($ Fig $3 \mathrm{C}, \mathrm{D})$. The results indicate that our mAbs, although recognizing the $\mathrm{A} \beta \mathrm{N}$-terminus, are conformation-sensitive and preferentially bind to the protofibrils even in presence of excessive concentrations of monomers, contrary to the positive control $A \beta N$-terminus antibody 6E10. 
a

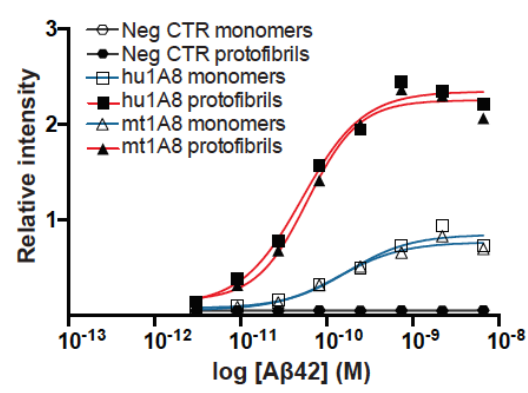

C

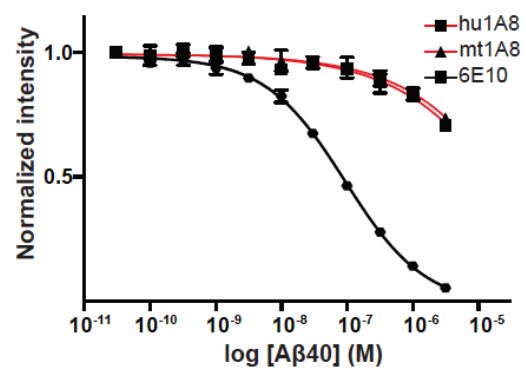

e
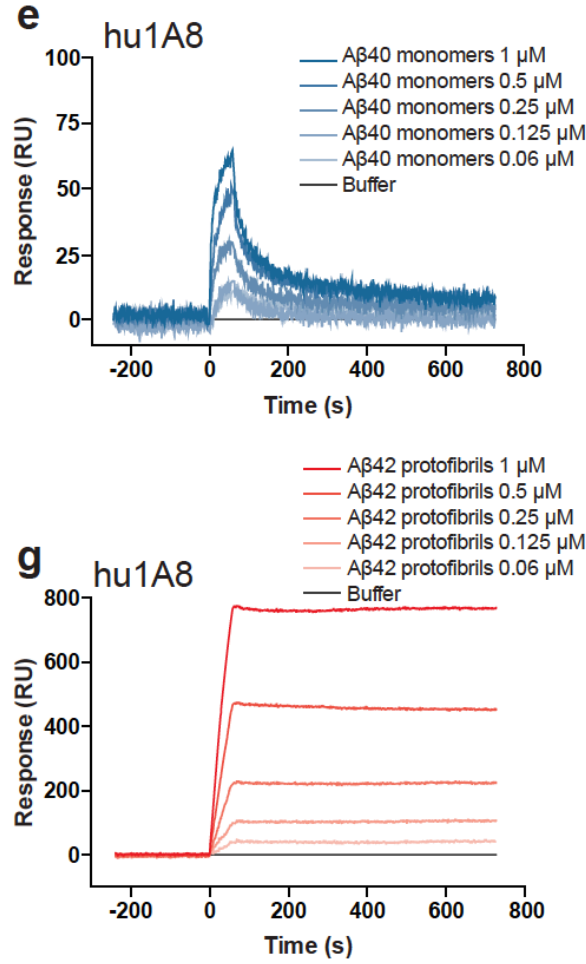

b

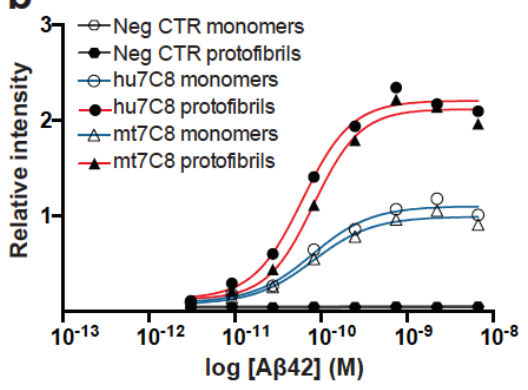

d
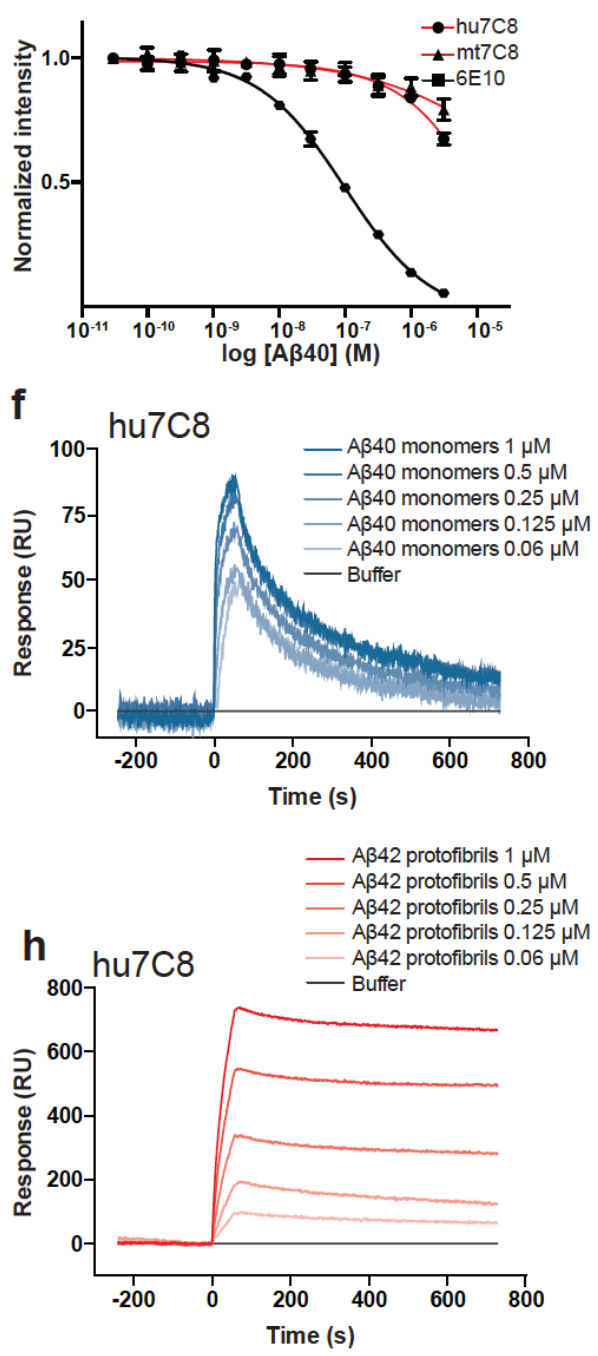

Figure 3. Conformation-sensitive binding of $1 A 8$ and 7C8 to AB42 monomers and protofibrils.

The relative binding of $1 A 8$ and $7 C 8$ to $A \beta 42$ monomers and protofibrils was tested by $(A-D)$ ELISA and (E-H) surface plasmon resonance (SPR). (A,B) Sandwich ELISA where human 
chimeric mAbs hu1A8 and hu7C8 (wildtype or effectorless mutant (mt)) are the capture antibodies for either $A \beta 42$ protofibrils or soluble monomeric $A \beta 40$. (C, D) Solution competition of antibodies (hu1A8, mt1A8, hu7C8, and mt7C8) to immobilized A 442 protofibrils by soluble monomeric A $A 40$, compared to the positive control 6E10 antibody. For the competition ELISA, Aß42 protofibrils were coated on the ELISA plate and incubated with the antibodies together with decreasing concentrations of $A \beta 40$ monomers. The binding of $(E, G)$ hu1A8 and $(F, H)$ hu7C8 to $(E, F) A \beta 40$ monomers and $(G, H) A \beta 42$ protofibrils was tested by SPR. AB40 monomers and $A \beta 42$ protofibrils were prepared at a $10 \mu \mathrm{M}$ initial concentration, diluted to $1,0.5$, $0.250,0.125$, and $0.06 \mu \mathrm{M}$ and flown for 60 s over each antibody (300 nM) previously immobilized on the chip $(R L=6500)$. Data are normalized by interspot and buffer and presented as mean \pm standard error of the mean (SEM).

Conformation-sensitivity was further characterized with a label-free SPR binding assay comparing monomer and protofibril affinity. The assay was validated using either the $\mathrm{N}$-terminal binding anti-A $\mathrm{BAb}, 6 \mathrm{E} 10$ (S5 Fig $A, C$ ), or a negative control mAb (S5 Fig B, D). The hu1A8 (Fig 3E) and hu7C8 (Fig 3F) mAbs immobilized on the chip surface showed a mild concentration-dependent binding to $A \beta 40$ monomers (Fig 3E, F), characterized by a rapid dissociation phase. In contrast, the antibodies binding to $A \beta 42$ protofibrils (Fig $3 G, H$ ) resulted in a potent and concentration-dependent association curve and lack of dissociation in the 800 seconds of observation.

\section{Functional inhibition of $A \beta 42$ aggregation by $1 \mathrm{~A} 8$ and $7 \mathrm{C} 8$}

Proteins that bind intermediate amyloid aggregates can have an effect on microscopic rate constants of aggregation kinetics [39]. Since $1 \mathrm{~A} 8$ and 7C8 have high affinity to the intermediate species (protofibrils), we aimed to determine the effect on microscopic aggregation events in the 
kinetic reaction. The whole molecule mAbs show inhibitory effect on equimolar concentration of Aß42 aggregation, as measured by the fluorescent signal decrease obtained with $1 \mathrm{~A} 8$ and $7 \mathrm{C} 8$ in a thioflavin T (ThT) kinetic reaction, compared with the control antibody (Fig 4A) (two-way ANOVA with repeated measure indicates a significant time * treatment interaction $\mathrm{F}_{(300,755)}=$ 34.23, $p<0.0001$, time effect $F_{(146,2774)}=457.0, p<0.0001$ and treatment effect $F_{(6,19)}=91.77, p$ $<0.0001)$. However, whereas 7C8 completely inhibits aggregation, 1A8 delays the initial reaction, although it fails to reduce final fibril content (Fig 4A) (one-way ANOVA on the endpoint fluorescence indicates significant treatment effect: $F_{(2,5)}=70.59, p<0.01$, followed by Dunnett's multiple comparison test). 


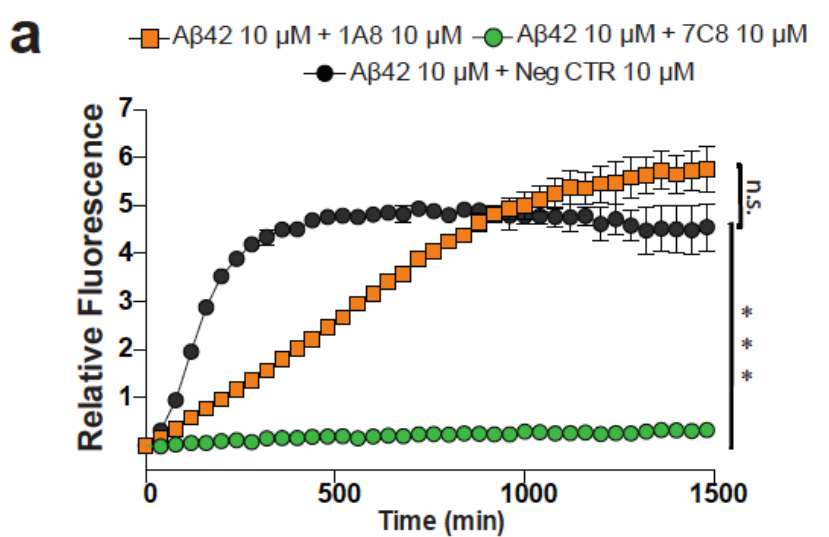

b - $-\mathrm{A} \beta 4210 \mu \mathrm{M}+1 \mathrm{~A} 8$ Fab $2.5 \mu \mathrm{M}-\mathrm{-}-\mathrm{A} \beta 4210 \mu \mathrm{M}+1 \mathrm{~A} 8$ Fab $7.5 \mu \mathrm{M}$ $\rightarrow-A \beta 4210 \mu \mathrm{M}+1 \mathrm{~A} 8$ Fab $5 \mu \mathrm{M}-\mathrm{a}-\mathrm{A} 4210 \mu \mathrm{M}+1 \mathrm{~A} 8$ Fab $10 \mu \mathrm{M}$

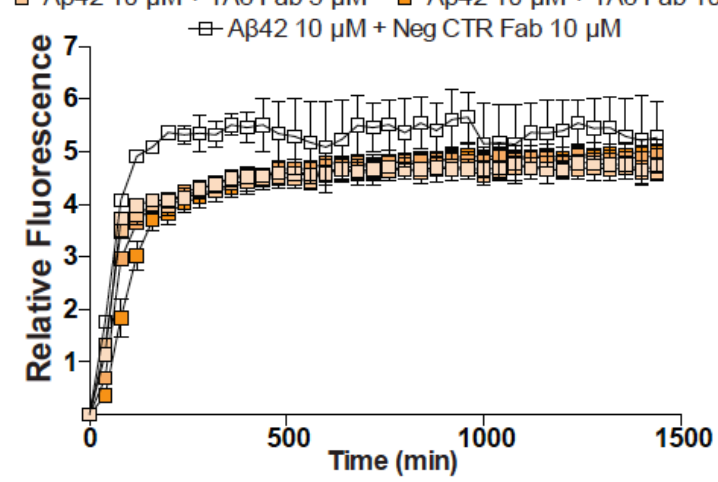

C $-\mathrm{O}-\mathrm{AB} 4210 \mu \mathrm{M}+7 \mathrm{C} 8$ Fab $2.5 \mu \mathrm{M}-\mathrm{O}-\mathrm{AB} 4210 \mu \mathrm{M}+7 \mathrm{C} 8$ Fab $7.5 \mu \mathrm{M}$ $-0-A \beta 4210 \mu \mathrm{M}+7 \mathrm{C} 8$ Fab $5 \mu \mathrm{M}-0-A \beta 4210 \mu \mathrm{M}+7 \mathrm{C} 8$ Fab $10 \mu \mathrm{M}$
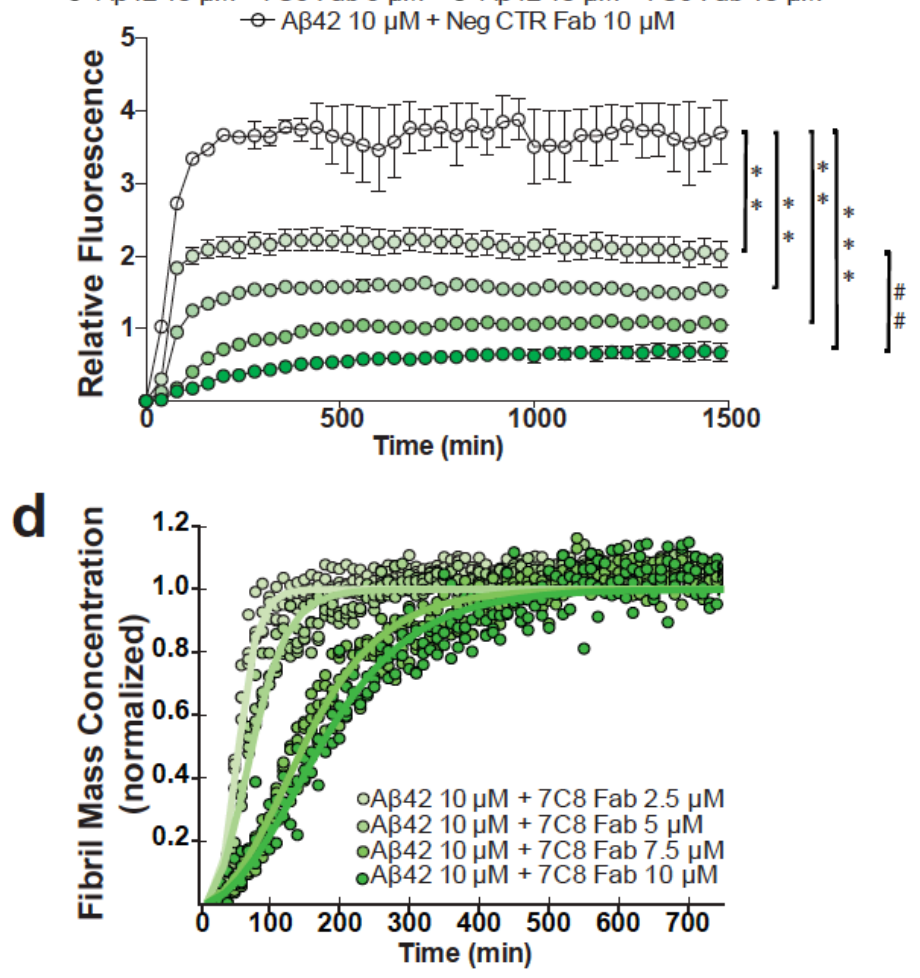

Figure 4. Inhibition of $A \beta 42$

\section{aggregation by $1 \mathrm{A8}$ and $7 C 8$.}

(A) Kinetics of aggregation of $10 \mu \mathrm{M}$

$A \beta 42$ incubated at $37^{\circ} \mathrm{C}$ for $24 \mathrm{~h}$ in

quiescent conditions, in presence of 10

$\mu M$ ThT and equimolar concentrations

of $1 A 8$ and $7 C 8 \lg G$, increasing

concentrations $(2.5,5,7.5$ and $10 \mu \mathrm{M})$

of digested (B) $1 A 8$ and (C) 7C8 Fab

fragments. An lgG1 isotype control

and the correspondent digested Fab

fragments were used as negative

controls. ${ }^{* *} p<0.01,{ }^{* *} p<0.0001$ vs

CTR antibody; \#\# $p<0.01$ vs lower

antibody concentration (post-hoc

comparison). (D) The aggregation

kinetics of $A \beta 42$ in presence of

increasing concentrations $(2.5,5,7.5$

and $10 \mu \mathrm{M}$ ) of digested 7C8 Fab

fragments (shown in panel C) was

analyzed by Amylofit. For each $m A b$

concentration the aggregation values

were normalized to 1 and the rate

constant parameters for secondary 
nucleation were individually fitted in parallel to global fitting of primary nucleation and elongation. Fitted (lines) and the experimental (circles) data are shown.

Subsequently, we obtained digested Fab fragments in order to control the antibody avidity effect and reduce the size of the inhibitory molecule. We found that $1 \mathrm{~A} 8 \mathrm{Fab}$ did not show significant functional effect when tested for the inhibition of $A \beta 42$ aggregation in the ThT assay (Fig 4B). The statistical analysis (two-way ANOVA with repeated measure) indicates a significant time * treatment interaction $\left(F_{(584,1898)}=6.058, p<0.0001\right)$ and time effect $\left(F_{(146,1898)}\right.$ $=488.0 \mathrm{p}<0.0001)$, but no significant treatment effect.

On the other hand, the 7C8 Fab fragments retain the inhibitory effect expressed by the full 7C8 IgG and potently and concentration-dependently decrease A $\beta 42$ aggregation and final fibril mass (Fig 4C). The inhibitory effect is expressed by both a delay in the aggregation, as seen by the progressive rightward shift of the curves with increasing Fab fragment concentration, and a significant reduction in the endpoint fluorescence, indicating decreased fibril mass after $24 \mathrm{~h}$ of co-incubation. The statistical analysis of the time course aggregation kinetics revealed a significant time * treatment interaction [two-way ANOVA with repeated measure (time) $\mathrm{F}_{(920,2990)}$ $=10.33 p<0.0001$, time effect $F_{(230,2990)}=137.6 p<0.0001$ and treatment effect $F_{(4,13)}=75.93$ $p<0.0001]$, and the analysis of the final fluorescence level indicates a significant treatment effect [one-way ANOVA $F_{(4,13)}=15.87 p<0.0001$, followed by Tukey's multiple comparisons test].

Recently, the rate kinetics for $A \beta$ aggregation have been scrutinized, allowing for the understanding of inhibitory effects on each microscopic mechanism [39]. Using the Amylofit software [40], we applied the curve fitting parameters to our primary data of 7C8 Fab-mediated $A \beta$ aggregation and found that the binding domain of the antibody inhibits aggregation with a dual mechanism (Fig 4D). The rate kinetics best fit with a multi-step secondary nucleation 
dominated model, thereby secondary nucleation as well as primary nucleation kinetics are affected by 7C8 Fab fragments (Fig 4D, S1 Table).

\section{Rescue of Aß42-induced cell toxicity by $1 \mathrm{~A} 8$ and $7 \mathrm{C} 8$}

To determine whether $1 \mathrm{~A} 8$ and $7 \mathrm{C} 8$ also bound to $A \beta$ in a biological context, we tested whether these antibodies could rescue $A \beta$-induced cytotoxicity in a cell-based system. To establish the assay, we treated adherent PC12 cells with a concentration range of either $A \beta 42$ monomers or protofibrils, and measured viability using the MTT reagent (Fig 5A). While we do not believe this assay is of physiological relevance to AD per se [44, 45], it provides a facile screen to measure binding of the antibodies to $A \beta$ in a biological matrix. The addition of $A \beta 42$ protofibrils was far more toxic than that of monomers, with $\mathrm{EC}_{50}$ around $10 \mathrm{nM}$ compared to 200 $\mathrm{nM}$ (Fig 5A). We next treated the cells with $1 \mathrm{~A} 8$ and $7 \mathrm{C} 8$ at the $\mathrm{EC}_{80}$ concentration of either Aß42 monomer (Fig 5B, D) or protofibril (Fig 5C, E) (30 nM and $800 \mathrm{nM}$, respectively). Both $1 \mathrm{~A} 8$ and 7C8 were able to rescue $A \beta 42-$ mediated toxicity with nanomolar potencies, though $1 \mathrm{~A} 8$ antibody variants had a reduced maximal effect compared with 7C8 variants. 


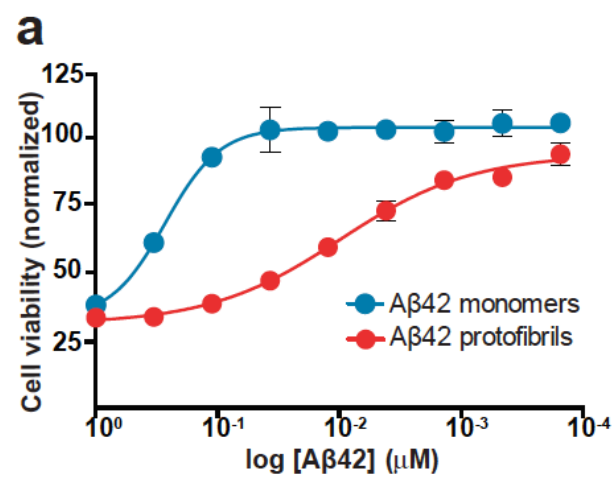

b

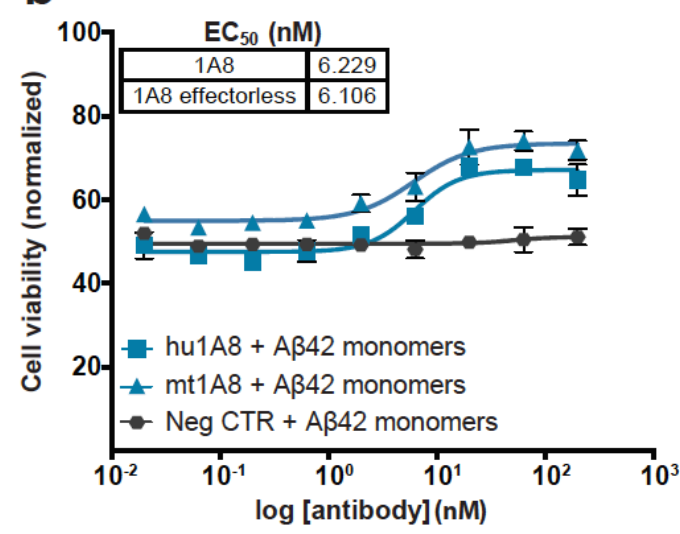

d

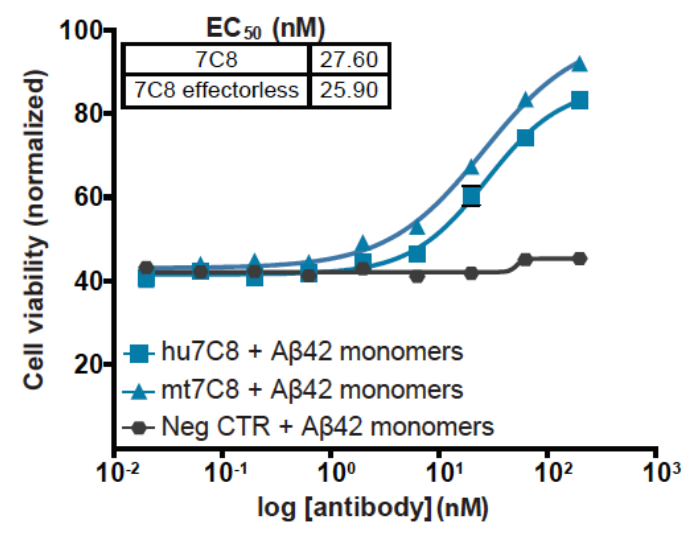

C

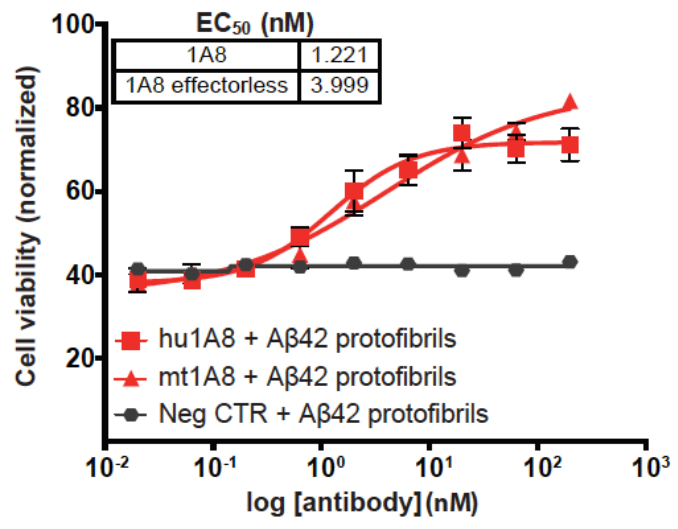

e

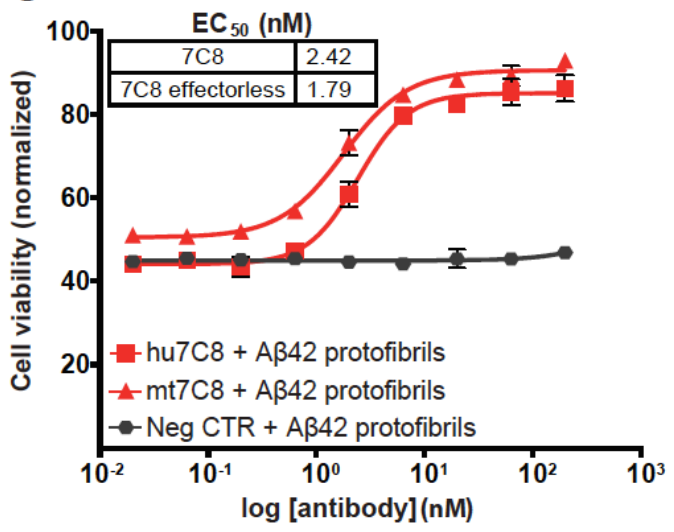

Figure 5. Inhibition of Aß42-mediated cell toxicity by $1 A 8$ and $7 C 8$.

A) Cytotoxicity mediated by A 42 monomers and protofibrils in PC12 cells. The viability of adherent PC12 cells was measured by MTT assay in presence of increasing concentrations of A 42 monomers or protofibrils, added to the plate at an initial concentration of $1 \mu \mathrm{M}$ and $3 \mu \mathrm{M}$, respectively, and incubated overnight. $(B, D)$ The viability of adherent $P C 12$ cells was measured by MTT assay in presence of $A \beta 42$ monomers ( $800 \mathrm{nM})$ or $(B, D)$ protofibrils (30 nM) and 
increasing concentrations of the human chimeric $(B, C) 1 A 8$ (hu1A8) or $(D, E) 7 C 8$ (hu7C8) and their respective effectorless proteins (mt1A8 and mt7C8). In each experiment, a human IgG1 was used as a negative isotype control, $A \beta 42$ plus a concentration range of antibodies was incubated with the cells overnight. Viability was then measured using the MTT kit.

\section{$1 \mathrm{~A} 8$ and $7 \mathrm{C} 8$ staining of PS1/APP mouse brain}

To determine if $1 \mathrm{~A} 8$ and 7C8 could stain amyloid aggregates in tissue, we performed immunohistochemistry on brain sections of a mouse model with amyloid deposition. The mouse model, PS1/APP, contains transgenes for both presenilin-1 with the L166P mutation and APP containing the Swedish mutation (KM670/671NL) [46]. These transgenes are under the control of the Thy 1 promoter, thereby limiting expression primarily to brain tissue. Both $1 \mathrm{~A} 8$ and $7 \mathrm{C} 8$ stain plaques in PS1/APP, comparable to a total A $\beta$ antibody (Fig 6). No specific staining was observed in non-transgenic mice or with an isotype control antibody (Fig S6).
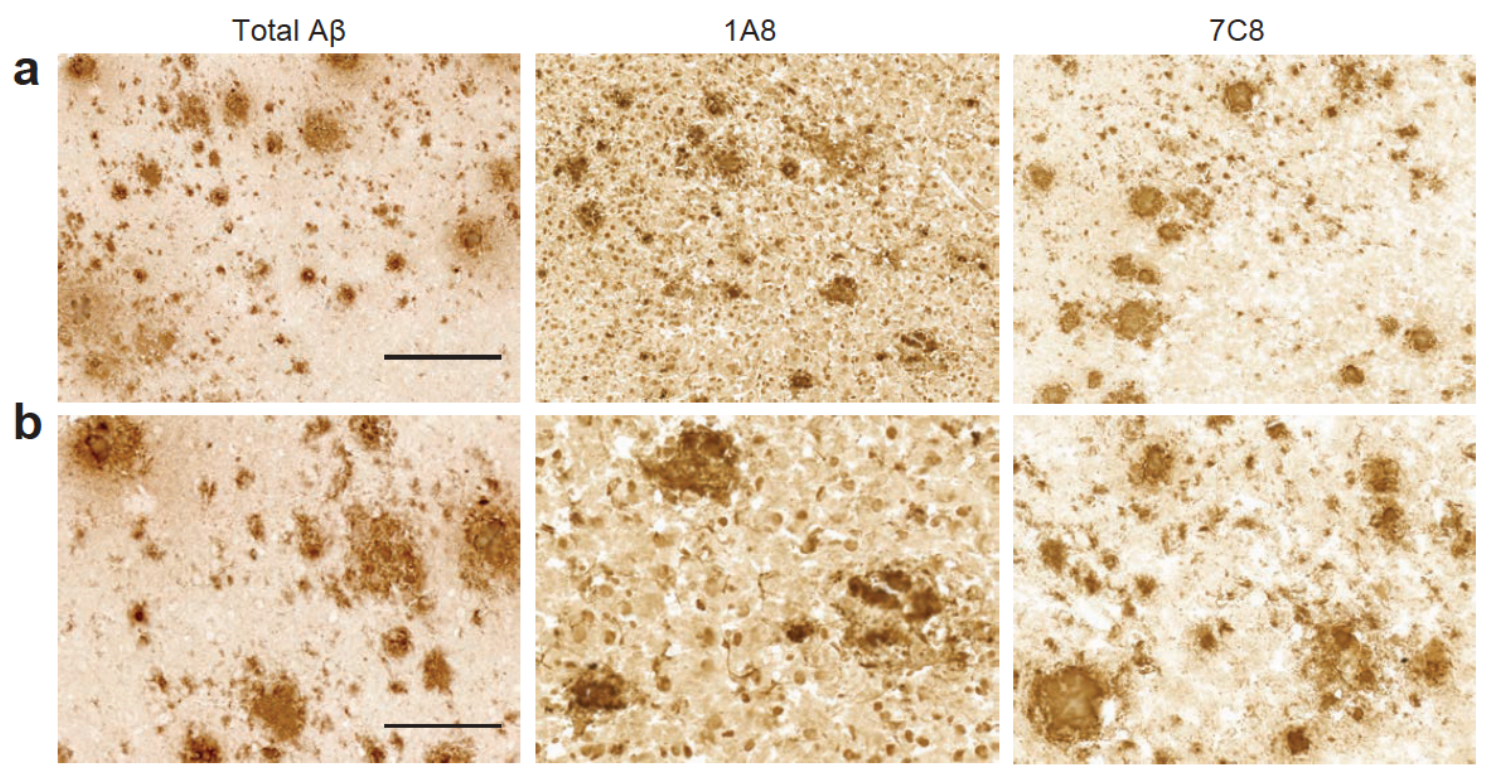

Figure 6. $1 A 8$ and 7C8 target reactivity in PS1/APP mouse brain.

The target reactivity of $1 A 8$ and $7 C 8$ was evaluated in tissue slices from PS1/APP mouse brain. $12 \mu m$ thick sections were post-fixed and stained with $1 A 8,7 C 8$, a positive control anti-A $\beta$ 
antibody, at $10 \mu \mathrm{g} / \mathrm{ml}$. The signal was detected with horseradish peroxidase (HRP)-based detection. (A) A larger field of view shows the density of plaque staining in the region. (scale bar $=250 \mu \mathrm{m})(B)$ A higher magnification shows dense and diffuse plaque staining. (scale bar $=100$ $\mu m)$

\section{$1 \mathrm{A8}$ and 7C8 staining of human AD frontal cortex}

Immunohistochemical studies were next conducted on human AD brain parenchyma.

Because of the N-terminal, yet conformation-sensitive activity of $1 \mathrm{~A} 8$ and $7 \mathrm{C} 8$, we analyzed the staining in adjacent serial sections of frontal cortex, and compared it with the anti-A $\beta \mathrm{N}$-terminus $6 \mathrm{E} 10$ antibody (Fig 7A). The staining pattern showed by $1 \mathrm{~A} 8$ and $7 \mathrm{C} 8$ revealed increased detection of dense neuritic plaques and large diffuse plaques within the same regions, compared with the positive control antibody (Fig 7B). Intraneuronal staining was observed with both $1 \mathrm{~A} 8$ and $7 \mathrm{C} 8$, and was particularly prevalent with $1 \mathrm{~A} 8$. Finally, parenchyma vessels were identified, revealing increased staining pattern around the vessels with both 1 A8 and 7C8 (Fig 7C). 


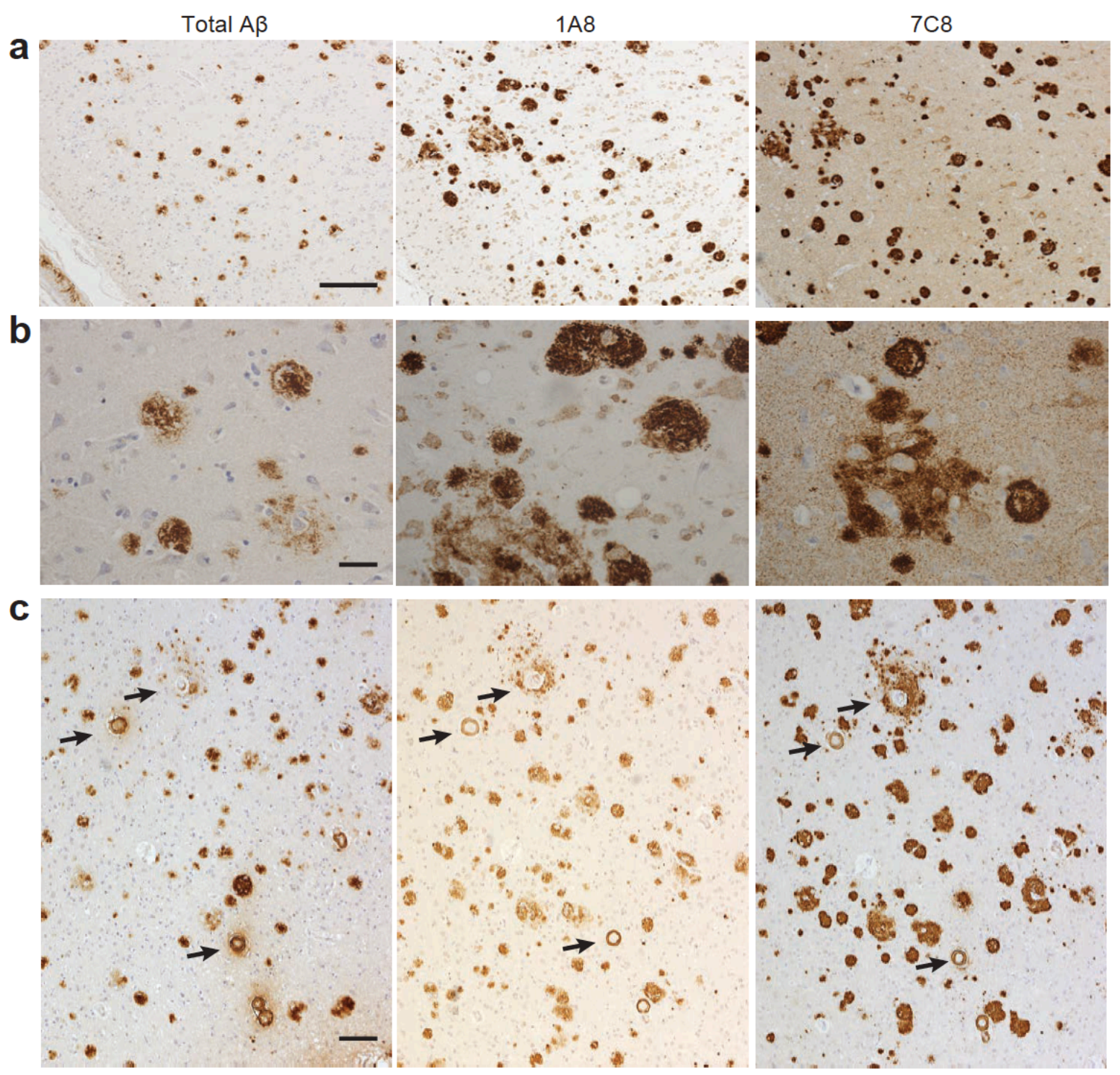

Figure 7. $1 A 8$ and $7 C 8$ target reactivity in human AD brains.

The target reactivity of $1 A 8$ and $7 C 8$ was evaluated in tissue slices from the frontal cortex of a patient diagnosed with $A D$ (Braak V-VI) and cerebral amyloid angiopathy. $5 \mu$ m thick consecutive formalin-fixed paraffin-embedded (FFPE) sections were stained with the positive control anti-A $\beta$ antibody, $6 E 10(1: 1000), 1 A 8(0.05 \mu \mathrm{g} / \mathrm{ml})$ or $7 C 8(0.05 \mu \mathrm{g} / \mathrm{ml})$. The signal was detected using an HRP-DAB based detection system and the nuclei counterstained with Mayer's hematoxylin. (A) A large field of view of serial sections shows dense and diffuse plaque staining with $1 A 8$ or $7 C 8$. (scale bar $=400 \mu m$ ) (B) A higher magnification shows intracellular 
staining with $1 A 8$ and $7 C 8$ that is absent with 6E10. (scale bar $=50 \mu \mathrm{m})(C)$ A large field of view shows staining around parenchymal vessels (arrows) in the frontal cortex. (scale bar = 100 $\mu m)$

\section{Discussion}

Therapeutic application of conformation-selective anti-amyloid antibodies that target the pathophysiological forms of the soluble amyloid intermediate is a compelling approach to disease mitigation. Although an unproven strategy to address the huge unmet need for diseasemodifying therapeutics for $A D$, there are four biologics in clinical trials that have reactivity against aggregated forms of $A \beta$. Developing conformation-selective antibodies to the extremely transient intermediate in amyloid aggregation has been a challenge. The present study describes the use of a novel CLABP, $m+N U C B 1$, which stabilizes soluble $A \beta 42$ protofibrillar structures [32] for use as immunogen for the discovery of conformation-sensitive, anti-A $\beta$ protofibril mAbs (Fig 1). We hypothesized that the $m+N U C B 1$-capped A 342 protofibrils would provide neoepitopes that retain protofibril structural characteristics.

mtNUCB1-capped A 42 protofibrils were enriched using SEC and tested with ELISA, AFM and immunoEM (S1 Fig). The results recapitulate our previous observations that $m+N U C B 1-A \beta$ protofibrils constitute a stable complex [32]. The campaign using the $m \mathbb{N}$ UCB1-A $\beta$ protofibril as an immunogen in mice yielded a range of activity measured from the supernatants of isolated cell populations (Fig 2A). The results of the primary screening indicate that the supernatant fractions had reactivity against $A \beta$ protofibrils alone, $m \mathbb{N}$ UCB1 alone, and in some cases, mixed reactivity against both protofibrils and $m+N U C B 1$ (Fig 2B). We chose 57 hybridomas with the highest reactivity to $A \beta 42$ protofibrils for subsequent secondary screening by single-point ELISA to assess binding to $A \beta 42$ monomers, protofibrils, $m+N U C B 1-A \beta 42$ protofibrils, and $m+\mathbb{N} U C B 1$

(Fig 2B). Based on their binding profile, 24 clones (showed in Fig 2B, lower panel) were 
selected to measure $A \beta$ protofibril-selective binding by the label-free Octet assay (S2 Fig A) and to determine the affinity to the peptide $\mathrm{N}$-terminus by SPR (S2 Fig B).

Based on the knowledge that aducanumab is a high-affinity, conformation-selective anti-A $\beta$ protofibril $m A b$ that has reactivity against residues 3-6 on $A \beta[47,48]$, we selected from the secondary screen five antibodies that showed N-terminus binding: two antibodies with the lowest and highest binding signal, $1 \mathrm{~A} 8$ and 7C8, respectively, and three antibodies with an intermediate binding signal (1D9, 1E7, and 6G2). These five antibodies were sequenced, subcloned and re-tested for their conformation-selectivity by sandwich ELISA. The clones showed a similar profile with moderate activity against the monomeric peptide and higher binding to A 342 protofibrils (S3 Fig). Therefore, among those five N-terminal mAbs with preferential binding to protofibrils, we ultimately selected the two mAbs with lowest and highest $\mathrm{N}$-terminal activity, 1A8 and 7C8, and thoroughly characterized them in different assays.

First, in order to evaluate $1 \mathrm{~A} 8$ and 7C8 conformation-sensitive activity, we tested their binding to $A \beta$ monomers and protofibrils in a sandwich ELISA assay (Fig 3A, B), a solution competition ELISA (Fig 3C, D), and with SPR (Fig 3E-H). Our results indicate that, despite binding to the $\mathrm{N}$-terminal $A \beta$ peptide, both mAbs preferentially bind to protofibrils over monomers. The solution competition ELISA displays comparable results to that reported for aducanumab [48]. When conformation reactivity is measured by SPR, the mAbs-monomer binding is followed by an almost complete dissociation curve (Fig 3E, F), but the mAbsprotofibril association seems to be extremely strong and resistant to spontaneous dissociation (Fig 3G, H). These results could at least be partially explained by the observation that the $A \beta N$ terminus is a disordered extension from the aggregate core $[49,50]$ and thus binding activity could yield an avidity effect. Furthermore, the association curve produced by $1 \mathrm{~A} 8$ binding to monomers is reduced compared to $7 \mathrm{C} 8$, in line with a lower $1 \mathrm{~A} 8 \mathrm{~N}$-terminal affinity, as previously shown in Supplementary Fig 2B. 
To determine if the binding of these mAbs had a functional effect on $A \beta$ aggregation in vitro, we performed a kinetic ThT aggregation assay. We observed that, while 7C8 completely inhibited equimolar concentrations of $A \beta 42,1 A 8$ only exhibited a mild effect as can be observed by a delay in the aggregation curve (Fig 4A). Interestingly, when the experiment employed Fab fragments digested from 1A8, we observed a loss of inhibitory activity (Fig 4B), suggesting that the inhibition of aggregation expressed by the $1 \mathrm{~A} 8$ full $\lg G$ molecule is likely due to a combined two-site binding effect lacking strong $\mathrm{N}$-terminal binding.

On the other hand, 7C8 Fab fragments retained the mAb inhibitory activity as indicated by a significant and concentration-dependent inhibition of aggregation (Fig 4C vs 4A). The analysis of the rate kinetics for $A \beta$ aggregation in the presence of increasing concentrations of $7 \mathrm{C} 8 \mathrm{Fab}$ fragments indicates that the inhibitory effect is exerted through a dual mechanism by interference with both the primary and the secondary nucleation (Fig 4D). This observation is in line with the hypothesis that 7C8 can bind structural elements required for secondary nucleation inhibition, but also binds the $N$-terminus of $A \beta$, thereby inhibiting primary nucleation events.

Altogether, these data are consistent with the $\mathrm{N}$-terminal binding profile reported in Supplemental Fig 2B, with $1 \mathrm{~A} 8$ and $7 \mathrm{C} 8$ showing low and high N-terminal binding signal, respectively. In fact, the $\mathrm{N}$-terminus activity expressed by 7C8 (S2 Fig B) combined with the other results indicates that this mAb likely binds to both monomers and protofibrils, therefore inhibiting the early stages of the amyloid aggregation and resulting, in turn, in potent aggregation inhibition (Fig $4 A, C) .1 A 8$, on the other hand, displays low binding affinity to the $A \beta$ N-terminus (S2 Fig B) and yet conformation-sensitive anti-protofibril activity (Fig 3A, C, E, G). Thus, the more mild inhibition of $A \beta 42$ aggregation by the full $1 A 8$ antibody (Fig $4 A$ ) is primarily exerted through aggregate binding with an avidity effect. The avidity feature of $1 \mathrm{~A} 8$ to the complex, multi-repeating epitopes on the amyloid aggregate highlights structural binding. 
The ideal therapeutic $\mathrm{mAb}$ would reduce $A \beta$ toxicity even in the absence of aggregate degradation or cellular clearance by microglial cells. We therefore employed a cellular assay of $A \beta$ toxicity using either $A \beta 42$ monomers or protofibrils as the starting material in a toxic insult. $1 \mathrm{~A} 8$ and $7 \mathrm{C} 8$ showed robust cyto-protection with $\mathrm{EC}_{50}$ ranges below $10 \mathrm{nM}$ or below $2 \mathrm{nM}$ for either monomer or protofibril insults, respectively (Fig 5). These results highlight the binding effect of $1 A 8$ and $7 C 8$ on $A \beta$ aggregates.

To visualize target binding ex vivo, we used immunohistochemistry on PS1/APP mouse brain and $A D$ human frontal cortex. The results show that both antibodies display plaque staining of both dense and diffuse phenotypes (Fig 6 and Fig 7). In serial sections of human AD brain, the number of diffuse and dense plaques were greater than that detected with the positive control, $A \beta N$-terminus $6 \mathrm{E} 10$ antibody. Additionally, both mAbs showed moderate intraneuronal staining, whereas this pattern was largely absent with 6E10 staining (Fig 7). The observed 1 A8 and 7C8 staining pattern was not due to reactivity with APP, since it differed with that of $6 \mathrm{E} 10$, an antibody known to recognize APP as well as A $\beta$. Furthermore, parenchymal vessels were stained with both antibodies and diffuse staining around vessels could be observed. Therefore, these mAbs may be useful tools for studying intraneuronal $A \beta$ protofibril accumulation or aggregate accumulation at parenchymal vessels.

\section{Conclusions}

We report the use of a novel protofibril immunogen that has been stabilized by the CLABP $m t N U C B 1$. The immunization campaign using this pan-amyloid, protofibril-capping CLABP in complex with $\mathrm{A} \beta 42$ protofibrils yielded at least two high-affinity, conformation-sensitive mAbs, $1 A 8$ and $7 C 8$, that preferentially bind the $A \beta 42$ protofibril over the $A \beta$ monomer, though with apparent varying binding modes. Because mtNUCB1 stabilizes protofibrils from multiple amyloid 
sources, this approach represents a platform technology for discovering anti-protofibril antibodies that are potentially diagnostic or therapeutic for many amyloidosis syndromes.

\section{Acknowledgements}

Funding for this project was provided through the Pfizer Centers for Therapeutic Innovation program, the Robertson Therapeutic Development Fund at Rockefeller University, the Eleanor Schwartz Charitable Trust, the Nicholson Exchange Program and the Swedish Brain Power at the Karolinska Institutet. Human brain tissue was kindly provided by the Brain Bank at Karolinska Institutet, which receives financial support from the Stockholm County Council (Core facility funding), StratNeuro Karolinska Institutet and Swedish Brain Power. We thank the Electron Microscopy Resource Facility and the Molecular Cytology Core Facility at Memorial Sloan-Kettering Cancer Center. We thank Dr. Carolina Adura of the Rockefeller University HighThroughput and Spectroscopy Resource Center for guidance and data interpretation in the use of the ProteOn XPR36 Protein Interaction Array system. We also thank Dr. Fergus Byrne for early contributions to the project and Prof. Bengt Winblad for advice and encouragement throughout.

Authors' contributions: WVG, ABO, PDW, and TPS designed the study. WVG and ABO prepared and characterized the immunogen, and conducted the experiments with the purified antibodies. RA, RK, KK, and $\mathrm{KM}$ supervised the immunization campaign and carried out the primary and secondary screening. JD performed the immunohistochemical studies on animal tissue and AL, MP, and CG performed studies on human tissue. WVG and ABO wrote the paper with critical input from CG, KMW, KM, PDW, TPS and all other authors who approved the final version. 


\section{References}

1. Winblad B, Amouyel P, Andrieu S, Ballard C, Brayne C, Brodaty H, et al. Defeating Alzheimer's disease and other dementias: a priority for European science and society. Lancet Neurol. 2016;15(5):455-532. doi: 10.1016/S1474-4422(16)00062-4. PubMed PMID: 26987701.

2. Graham WV, Bonito-Oliva A, Sakmar TP. Update on Alzheimer's Disease Therapy and Prevention Strategies. Annu Rev Med. 2017;68:413-30. doi: 10.1146/annurev-med-042915-103753. PubMed PMID: 28099083.

3. Cummings J, Lee G, Mortsdorf T, Ritter A, Zhong K. Alzheimer's disease drug development pipeline: 2017. Alzheimers Dement (N Y). 2017;3(3):367-84. doi: 10.1016/j.trci.2017.05.002. PubMed PMID: 29067343; PubMed Central PMCID: PMCPMC5651419.

4. Hardy JA, Higgins GA. Alzheimer's disease: the amyloid cascade hypothesis. Science. 1992;256(5054):184-5. PubMed PMID: 1566067.

5. Hardy J, Selkoe DJ. The amyloid hypothesis of Alzheimer's disease: progress and problems on the road to therapeutics. Science. 2002;297(5580):353-6. Epub 2002/07/20. doi:

10.1126/science.1072994. PubMed PMID: 12130773.

6. Goate A, Chartier-Harlin MC, Mullan M, Brown J, Crawford F, Fidani L, et al. Segregation of a missense mutation in the amyloid precursor protein gene with familial Alzheimer's disease. Nature. 1991;349(6311):704-6. doi: 10.1038/349704a0. PubMed PMID: 1671712.

7. Hung SY, Fu WM. Drug candidates in clinical trials for Alzheimer's disease. J Biomed Sci. 2017;24(1):47. doi: 10.1186/s12929-017-0355-7. PubMed PMID: 28720101; PubMed Central PMCID: PMCPMC5516350.

8. Sevigny J, Chiao P, Bussiere $T$, Weinreb PH, Williams L, Maier M, et al. The antibody aducanumab reduces A beta plaques in Alzheimer's disease. Nature. 2016;537(7618):50-6. doi: 10.1038/nature19323. PubMed PMID: WOS:000382426900036.

9. Sevigny J, Chiao P, Williams L, Chen T, Ling Y, O'Gorman J, et al. Aducanumab (BIIB037), an antiamyloid beta monoclonal antibody, in patients with prodromal or mild Alzheimer's disease: Interim results of a randomized, double-blind, placebo-controlled, phase $1 \mathrm{~b}$ study. Alzheimer's \& Dementia: The Journal of the Alzheimer's Association. 11(7):P277. doi: 10.1016/j.jalz.2015.07.367.

10. ladanza MG, Jackson MP, Hewitt EW, Ranson NA, Radford SE. A new era for understanding amyloid structures and disease. Nat Rev Mol Cell Biol. 2018;19(12):755-73. doi: 10.1038/s41580-0180060-8. PubMed PMID: 30237470.

11. Englund H, Sehlin D, Johansson AS, Nilsson LN, Gellerfors P, Paulie S, et al. Sensitive ELISA detection of amyloid-beta protofibrils in biological samples. Journal of neurochemistry. 2007;103(1):334-45. Epub 2007/07/12. doi: 10.1111/j.1471-4159.2007.04759.x. PubMed PMID: 17623042.

12. Sevigny J, Chiao P, Bussiere T, Weinreb PH, Williams L, Maier M, et al. The antibody aducanumab reduces Abeta plaques in Alzheimer's disease. Nature. 2016;537(7618):50-6. doi: 10.1038/nature19323. PubMed PMID: 27582220.

13. Conway KA, Rochet JC, Bieganski RM, Lansbury PT, Jr. Kinetic stabilization of the alpha-synuclein protofibril by a dopamine-alpha-synuclein adduct. Science. 2001;294(5545):1346-9. doi:

10.1126/science.1063522. PubMed PMID: 11701929.

14. Johansson AS, Garlind A, Berglind-Dehlin F, Karlsson G, Edwards K, Gellerfors P, et al. Docosahexaenoic acid stabilizes soluble amyloid-beta protofibrils and sustains amyloid-beta-induced neurotoxicity in vitro. The FEBS journal. 2007;274(4):990-1000. doi: 10.1111/j.1742-4658.2007.05647.x. PubMed PMID: 17227385. 
15. Hawkes CA, Deng LH, Shaw JE, Nitz M, McLaurin J. Small molecule beta-amyloid inhibitors that stabilize protofibrillar structures in vitro improve cognition and pathology in a mouse model of Alzheimer's disease. Eur J Neurosci. 2010;31(2):203-13. doi: 10.1111/j.1460-9568.2009.07052.x. PubMed PMID: 20074226.

16. Williams TL, Serpell LC, Urbanc B. Stabilization of native amyloid beta-protein oligomers by Copper and Hydrogen peroxide Induced Cross-linking of Unmodified Proteins (CHICUP). Biochim Biophys Acta. 2016;1864(3):249-59. doi: 10.1016/j.bbapap.2015.12.001. PubMed PMID: 26699836.

17. Hayden EY, Kaur P, Williams TL, Matsui H, Yeh SR, Rousseau DL. Heme Stabilization of alphaSynuclein Oligomers during Amyloid Fibril Formation. Biochemistry. 2015;54(30):4599-610. doi: 10.1021/acs.biochem.5b00280. PubMed PMID: 26161848; PubMed Central PMCID: PMCPMC4526360. 18. Ryan TM, Roberts BR, McColl G, Hare DJ, Doble PA, Li QX, et al. Stabilization of nontoxic Abetaoligomers: insights into the mechanism of action of hydroxyquinolines in Alzheimer's disease. The Journal of neuroscience : the official journal of the Society for Neuroscience. 2015;35(7):2871-84. doi: 10.1523/JNEUROSCI.2912-14.2015. PubMed PMID: 25698727.

19. Guivernau B, Bonet J, Valls-Comamala V, Bosch-Morato M, Godoy JA, Inestrosa NC, et al. Amyloid-beta Peptide Nitrotyrosination Stabilizes Oligomers and Enhances NMDAR-Mediated Toxicity. The Journal of neuroscience : the official journal of the Society for Neuroscience. 2016;36(46):11693703. doi: 10.1523/JNEUROSCI.1081-16.2016. PubMed PMID: 27852777.

20. Cerf E, Gustot A, Goormaghtigh E, Ruysschaert JM, Raussens V. High ability of apolipoprotein E4 to stabilize amyloid-beta peptide oligomers, the pathological entities responsible for Alzheimer's disease. FASEB journal : official publication of the Federation of American Societies for Experimental Biology. 2011;25(5):1585-95. doi: 10.1096/fj.10-175976. PubMed PMID: 21266538.

21. Hayden EY, Conovaloff JL, Mason A, Bitan G, Teplow DB. Preparation of pure populations of covalently stabilized amyloid beta-protein oligomers of specific sizes. Anal Biochem. 2017;518:78-85. doi: 10.1016/j.ab.2016.10.026. PubMed PMID: 27810329; PubMed Central PMCID: PMCPMC5474095. 22. Williams AD, Sega M, Chen M, Kheterpal I, Geva M, Berthelier V, et al. Structural properties of Abeta protofibrils stabilized by a small molecule. Proceedings of the National Academy of Sciences of the United States of America. 2005;102(20):7115-20. doi: 10.1073/pnas.0408582102. PubMed PMID: 15883377; PubMed Central PMCID: PMCPMC1091746.

23. Sandberg A, Luheshi LM, Sollvander S, Pereira de Barros T, Macao B, Knowles TP, et al. Stabilization of neurotoxic Alzheimer amyloid-beta oligomers by protein engineering. Proceedings of the National Academy of Sciences of the United States of America. 2010;107(35):15595-600. doi: 10.1073/pnas.1001740107. PubMed PMID: 20713699; PubMed Central PMCID: PMCPMC2932621. 24. Kayed R, Head E, Thompson JL, McIntire TM, Milton SC, Cotman CW, et al. Common structure of soluble amyloid oligomers implies common mechanism of pathogenesis. Science. 2003;300(5618):486-9. doi: 10.1126/science.1079469. PubMed PMID: 12702875.

25. Gronwall C, Jonsson A, Lindstrom S, Gunneriusson E, Stahl S, Herne N. Selection and characterization of Affibody ligands binding to Alzheimer amyloid beta peptides. J Biotechnol. 2007;128(1):162-83. doi: 10.1016/j.jbiotec.2006.09.013. PubMed PMID: 17088007.

26. Lindgren J, Wahlstrom A, Danielsson J, Markova N, Ekblad C, Graslund A, et al. N-terminal engineering of amyloid-beta-binding Affibody molecules yields improved chemical synthesis and higher binding affinity. Protein science : a publication of the Protein Society. 2010;19(12):2319-29. doi: 10.1002/pro.511. PubMed PMID: 20886513; PubMed Central PMCID: PMC3009399.

27. Hageman J, Rujano MA, van Waarde MA, Kakkar V, Dirks RP, Govorukhina N, et al. A DNAJB chaperone subfamily with HDAC-dependent activities suppresses toxic protein aggregation. Mol Cell. 2010;37(3):355-69. doi: 10.1016/j.molcel.2010.01.001. PubMed PMID: 20159555.

28. Mansson C, Kakkar V, Monsellier E, Sourigues Y, Harmark J, Kampinga HH, et al. DNAJB6 is a peptide-binding chaperone which can suppress amyloid fibrillation of polyglutamine peptides at 
substoichiometric molar ratios. Cell Stress Chaperones. 2014;19(2):227-39. doi: 10.1007/s12192-0130448-5. PubMed PMID: 23904097; PubMed Central PMCID: PMCPMC3933622.

29. Mansson C, Arosio P, Hussein R, Kampinga HH, Hashem RM, Boelens WC, et al. Interaction of the molecular chaperone DNAJB6 with growing amyloid-beta 42 (Abeta42) aggregates leads to substoichiometric inhibition of amyloid formation. The Journal of biological chemistry. 2014;289(45):3106676. doi: 10.1074/jbc.M114.595124. PubMed PMID: 25217638; PubMed Central PMCID: PMCPMC4223311.

30. Willander H, Presto J, Askarieh G, Biverstal H, Frohm B, Knight SD, et al. BRICHOS domains efficiently delay fibrillation of amyloid beta-peptide. The Journal of biological chemistry. 2012;287(37):31608-17. doi: 10.1074/jbc.M112.393157. PubMed PMID: 22801430; PubMed Central PMCID: PMCPMC3438992.

31. Beeg M, Stravalaci M, Romeo M, Carra AD, Cagnotto A, Rossi A, et al. Clusterin Binds to Abeta142 Oligomers with High Affinity and Interferes with Peptide Aggregation by Inhibiting Primary and Secondary Nucleation. The Journal of biological chemistry. 2016;291(13):6958-66. doi: 10.1074/jbc.M115.689539. PubMed PMID: 26884339; PubMed Central PMCID: PMCPMC4807280. 32. Bonito-Oliva A, Barbash S, Sakmar TP, Graham WV. Nucleobindin 1 binds to multiple types of pre-fibrillar amyloid and inhibits fibrillization. Sci Rep. 2017;7:42880. doi: 10.1038/srep42880. PubMed PMID: 28220836; PubMed Central PMCID: PMCPMC5318909.

33. Gupta R, Kapoor N, Raleigh DP, Sakmar TP. Nucleobindin 1 Caps Human Islet Amyloid Polypeptide Protofibrils to Prevent Amyloid Fibril Formation. Journal of molecular biology. 2012. Epub 2012/05/01. doi: 10.1016/j.jmb.2012.04.017. PubMed PMID: 22542527.

34. Kilkenny C, Browne WJ, Cuthill IC, Emerson M, Altman DG. Improving bioscience research reporting: the ARRIVE guidelines for reporting animal research. PLoS biology. 2010;8(6):e1000412. doi: 10.1371/journal.pbio.1000412. PubMed PMID: 20613859; PubMed Central PMCID: PMCPMC2893951. 35. Greenfield EA. Generating Monoclonal Antibodies. In: Greenfield EA, editor. Antibodies: A Laboratory Manual. Second ed2014. p. 201-37.

36. Feinberg H, Saldanha JW, Diep L, Goel A, Widom A, Veldman GM, et al. Crystal structure reveals conservation of amyloid-beta conformation recognized by 3D6 following humanization to bapineuzumab. Alzheimers Res Ther. 2014;6(3):31. doi: 10.1186/alzrt261. PubMed PMID: 25024748; PubMed Central PMCID: PMCPMC4095729.

37. Myszka DG. Improving biosensor analysis. J Mol Recognit. 1999;12(5):279-84. doi: 10.1002/(SICl)1099-1352(199909/10)12:5<279::AID-JMR473>3.0.CO;2-3. PubMed PMID: 10556875. 38. Bravman T, Bronner V, Lavie K, Notcovich A, Papalia GA, Myszka DG. Exploring "one-shot" kinetics and small molecule analysis using the ProteOn XPR36 array biosensor. Anal Biochem. 2006;358(2):281-8. doi: 10.1016/j.ab.2006.08.005. PubMed PMID: 16962556.

39. Arosio P, Michaels TC, Linse S, Mansson C, Emanuelsson C, Presto J, et al. Kinetic analysis reveals the diversity of microscopic mechanisms through which molecular chaperones suppress amyloid formation. Nat Commun. 2016;7:10948. doi: 10.1038/ncomms10948. PubMed PMID: 27009901; PubMed Central PMCID: PMCPMC4820785.

40. Meisl G, Kirkegaard JB, Arosio P, Michaels TC, Vendruscolo M, Dobson CM, et al. Molecular mechanisms of protein aggregation from global fitting of kinetic models. Nat Protoc. 2016;11(2):252-72. doi: 10.1038/nprot.2016.010. PubMed PMID: 26741409.

41. Dalgediene I, Lasickiene R, Budvytyte R, Valincius G, Morkuniene R, Borutaite V, et al. Immunogenic properties of amyloid beta oligomers. J Biomed Sci. 2013;20:10. doi: 10.1186/1423-012720-10. PubMed PMID: 23432787; PubMed Central PMCID: PMCPMC3599114.

42. Xu D, Alegre ML, Varga SS, Rothermel AL, Collins AM, Pulito VL, et al. In vitro characterization of five humanized OKT3 effector function variant antibodies. Cell Immunol. 2000;200(1):16-26. doi: 10.1006/cimm.2000.1617. PubMed PMID: 10716879. 
43. Wang $X$, Mathieu M, Brezski RJ. IgG Fc engineering to modulate antibody effector functions. Protein Cell. 2018;9(1):63-73. doi: 10.1007/s13238-017-0473-8. PubMed PMID: 28986820; PubMed Central PMCID: PMCPMC5777978.

44. Rönicke R, Klemm A, Meinhardt J, Schröder UH, Fändrich M, Reymann KG. A $\beta$ Mediated Diminution of MTT Reduction-An Artefact of Single Cell Culture? PLOS ONE. 2008;3(9):e3236. doi: 10.1371/journal.pone.0003236.

45. Wogulis M, Wright S, Cunningham D, Chilcote T, Powell K, Rydel RE. Nucleation-dependent polymerization is an essential component of amyloid-mediated neuronal cell death. The Journal of neuroscience : the official journal of the Society for Neuroscience. 2005;25(5):1071-80. Epub 2005/02/04. doi: 10.1523/jneurosci.2381-04.2005. PubMed PMID: 15689542.

46. Radde R, Bolmont T, Kaeser SA, Coomaraswamy J, Lindau D, Stoltze L, et al. Abeta42-driven cerebral amyloidosis in transgenic mice reveals early and robust pathology. EMBO Rep. 2006;7(9):940-6. doi: 10.1038/sj.embor.7400784. PubMed PMID: 16906128; PubMed Central PMCID: PMCPMC1559665. 47. Murray B, Sharma B, Belfort G. N-Terminal Hypothesis for Alzheimer's Disease. ACS Chem Neurosci. 2017;8(3):432-4. doi: 10.1021/acschemneuro.7b00037. PubMed PMID: 28186729.

48. Arndt JW, Qian F, Smith BA, Quan C, Kilambi KP, Bush MW, et al. Structural and kinetic basis for the selectivity of aducanumab for aggregated forms of amyloid-beta. Sci Rep. 2018;8(1):6412. doi: 10.1038/s41598-018-24501-0. PubMed PMID: 29686315; PubMed Central PMCID: PMCPMC5913127. 49. Luhrs T, Ritter C, Adrian M, Riek-Loher D, Bohrmann B, Dobeli H, et al. 3D structure of Alzheimer's amyloid-beta(1-42) fibrils. Proceedings of the National Academy of Sciences of the United States of America. 2005;102(48):17342-7. doi: 10.1073/pnas.0506723102. PubMed PMID: 16293696; PubMed Central PMCID: PMCPMC1297669.

50. Torok M, Milton S, Kayed R, Wu P, McIntire T, Glabe CG, et al. Structural and dynamic features of Alzheimer's Abeta peptide in amyloid fibrils studied by site-directed spin labeling. The Journal of biological chemistry. 2002;277(43):40810-5. doi: 10.1074/jbc.M205659200. PubMed PMID: 12181315. 